\title{
ESPAÑA EN LA POLÍTICA EXTERIOR COMÚN EUROPEA: LOS ÚLTIMOS DIEZ AÑOS (2001-2011)
}

\author{
Mercedes Guinea ${ }^{1}$ \\ Universidad Complutense de Madrid (UCM)
}

\begin{abstract}
Resumen:
España es uno de los países que más cambios ha sufrido como consecuencia de su incorporación a la Unión Europea en 1986, en un proceso continuo de europeización. Igualmente España con su complejidad ha contribuido con los demás Estados miembros a lo que hoy es la Unión Europea. En este trabajo nos proponemos examinar la relación bidireccional entre la política exterior española y la europea en el periodo que va desde 2001 hasta 2011 como un caso de estudio aplicado de europeización. En ese tiempo se han turnado al frente del Gobierno de España dos partidos políticos Partido Popular (PP) y Partido Socialista Obrero Español (PSOE) con una visión diferente y, en ocasiones hasta incompatible, del papel de España en Europa y de su política exterior. Cabe, por tanto, analizar por separado cada una de esas fases desde diferentes puntos de vista: el contexto internacional y europeo, la visión y el proyecto político exterior del Gobierno, sus alianzas en el seno europeo e internacional, las dos vertientes de la europeización de la política exterior española (top-down y bottom-up), así como la participación española en la Política Europea de Seguridad y Defensa. En este análisis, además, pondremos especial énfasis en analizar el papel español en los momentos en que le tocó liderar la PESC, esto es, las dos Presidencias rotatorias del Consejo de la UE en 2002 y 2010. De la comparación de todas estas variables podrán trazarse unas conclusiones que nos ofrezcan las constantes de la política exterior europea de España así como las divergencias coyunturales.
\end{abstract}

Palabras clave: España, Unión Europea, política exterior española, PESC, europeización.

Title in English: “Spain's Role in the European Common Foreign Policy: The last Decade (2001-2011)”.

\section{Abstract:}

Spain has undergone profound transformations as result of its accession to the European Union in 1986, on a steady process of europeanization. This article examines the bidirectional influence between Spanish foreign policy and European Common Foreign and Security Policy between 2001 and 2011 as an example of europeanization. During this period the Spanish Government was led by two political parties, the Conservative Party (PP) and the Socialists (PSOE), which had different visions about Spanish role in Europe and Spanish foreign policy. We will analyze these two distinct phases from different points of view: international and European contexts, both Governments visions and perceptions of European political project, their international and European alliances, paths of Europeanization (top-down y bottom-up), and Spanish participation in European Security and Defence Policy. We will pay special attention to the periods when Spain was at the helm of the European Union, in 2002 and 2010.

Keywords: Spain, European Union, Spanish foreign policy, CFSP, Europeanization.

Copyright (C) UNISCI, 2011.

Las opiniones expresadas en estos artículos son propias de sus autores, y no reflejan necesariamente la opinión de UNISCI. The views expressed in these articles are those of the authors, and do not necessarily reflect the views of UNISCI.

\footnotetext{
${ }^{1}$ Mercedes Guinea es Profesora de Relaciones Internacionales de la Universidad Complutense de Madrid. Titular del Módulo Europeo Jean Monnet de la Comisión Europea sobre "La aplicación del Tratado de Lisboa: efectos en el modelo político, económico y social”. Email: mercedes.guinea@ telefonica.net. http://dx.doi.org/10.5209/rev_UNIS.2011.v27.38139
} 


\section{Consideraciones generales}

En el año 2011 se cumple el veinticinco aniversario de la incorporación de España a la entonces Comunidad Europea, hoy Unión Europea, cuestión que por diversos factores ha pasado extrañamente desapercibida entre nosotros ${ }^{2}$. Esos veinticinco años han resultado de vital importancia en el desarrollo político de ambos actores. En el caso de España, ha pasado de ser un país marginal en el juego político internacional, tanto por la estructura de la sociedad internacional de la época como por sus propios condicionantes internos, a ser una potencia media del sistema internacional. Examinando la Comunidad Europea-Unión Europea, la evolución no reviste una importancia menor. En estos últimos veinticinco años ha cambiado su naturaleza, de un mero Mercado Común que funcionaba relativamente bien a un sistema político singular ${ }^{3}$. Ha alcanzado desde el punto de vista económico una mayor integración, especialmente a través de la Moneda Única, y que desde el punto de vista político quiere ser percibido como un actor internacional relevante, con una política exterior global, y que desempeñe cada día más papeles en la escena internacional ${ }^{4}$.

En esta relevante evolución interconectada nos gustaría analizar el papel que España ha desempeñado en uno de los ámbitos de la acción común europea, la Política Exterior Común, eligiendo como periodo de estudio los últimos diez años, desde 2001 a 2011. Tradicionalmente, la doctrina ha valorado positivamente la relación entre España y la política exterior europea en una doble dimensión. Por una parte, la europeización de su política exterior le ha permitido a España superar los lastres de la política exterior heredada de la época franquista y consolidarse como una potencia de tamaño medio creíble. Por otra parte, la política exterior europea se enriquecería con la aportación de dos de las áreas preferenciales de relación española, dando impulso tanto a la Política Euromediterránea como a la Eurolatinoamericana en la década de los noventa ${ }^{5}$. Tampoco podemos olvidar la relevante aportación personal de españoles que han dejado su impronta en áreas de la Política Exterior Común ${ }^{6}$.

\footnotetext{
${ }^{2}$ Siendo una cuestión marginal a nuestro tema, no podemos dejar de referirnos a la nula conmemoración en nuestro país del veinticinco aniversario, en contraposición con los fastos de los veinte años en 2006. Ese bajo perfil político, indudablemente, se explica tanto por la falta de fondos públicos, como por un Gobierno acorralado por la crisis económica y la política. No obstante, es una lástima que se pierda esta ocasión de socialización de los beneficios de la integración europea entre la ciudadanía.

${ }^{3}$ Sobre la mutación o cambio de naturaleza de la integración europea, desde unas organizaciones de naturaleza económica a un sistema político complejo, véase: Aldecoa, Francisco (2002): La integración europea: génesis y desarrollo de la Unión Europea (1979-2002), Madrid; Tecnos; Quermonne, Jean-Louis, (2005): Le système politique européen, $7^{\mathrm{a}}$ ed., Paris, Montchrestien; Sidjanski, Dusan (1998): El futuro federalista de Europa. De los orígenes de la Comunidad a la Unión Europea, Barcelona, Ariel.

${ }^{4}$ Es preciso recordar que España resultó un actor fundamental en la profundización política de la integración europea, con un rol muy activo y federalista en la negociación del Tratado de Maastricht, que condujo a la creación de la PESC. Para un examen exhaustivo de las negociaciones, véase: Cloos, Jim; Reinesch, Gaston ; Vignes, Daniel y Weyland, Joseph, (1994) : Le traité de Maastricht: genèse, analyse et commentaires, Bruxelles, Bruylant.

5 Aldecoa Luzárraga, Francisco: "Veinte años de Portugal y España en la Unión Europea”, en: García Pérez, Rafael y Lob-Fernandes, Luís (Co.) (2007): España y Portugal. Veinte años de integración europea, Santiago de Compostela, Tórculo Edicións, pp. 89-116.

${ }^{6}$ A todos viene a la memoria el papel de Javier Solana, único Alto Representante para la PESC en la historia de ese puesto político. Pero tampoco puede desdeñarse el papel de otros relevantes diplomáticos y directores de política exterior. Así cabe citar, entre otros, a Eneko Landáburu, Director General de Relaciones Exteriores en la Comisión Europea de 2003 a 2009, el segundo por debajo del Comisario/-a, a Alberto Navarro, Director de ECHO, o a Migel Angel Moratinos, Representante Especial de la UE en el conflicto palestino-israelí.
} 
En este trabajo examinaremos, la relación bidireccional entre la política exterior española y la europea deteniéndonos concretamente en el periodo que va desde 2001 hasta 2011. Puede anticiparse que la valoración es compleja: si la década de los noventa era el momento de la puesta en marcha de la Política Exterior y de Seguridad Común (PESC), la actual es la del análisis de sus resultados y limitaciones, lo que ya no permite conclusiones tan optimistas. En ese periodo se han turnado al frente del Gobierno de España dos partidos políticos Partido Popular (PP) y Partido Socialista Obrero Español (PSOE) con una visión diferente y, en ocasiones hasta incompatible, del papel de España en Europa y de su política exterior.

Cabe, por tanto, analizar por separado cada una de esas fases desde diferentes puntos de vista: el contexto internacional y europeo, la visión y el proyecto político exterior del Gobierno, sus alianzas en el seno europeo e internacional, las dos vertientes de la europeización de la política exterior española (top-down y bottom-up), así como la participación española en la Política Europea de Seguridad y Defensa. En este análisis, además, pondremos especial énfasis en analizar el papel español en los momentos en que le tocó liderar la PESC, esto es, las dos Presidencias rotatorias del Consejo de la UE en 2002 y $2010^{7}$. De la comparación de todas estas variables podrán trazarse unas conclusiones que nos ofrezcan las constantes de la política exterior europea de España así como las divergencias coyunturales.

\section{Europa en la política exterior española, España en la política exterior europea}

La doctrina está de acuerdo en considerar que la adhesión a la entonces Comunidad Europea en el año 1986 es un factor decisivo para que España superara su tradicional aislamiento internacional y se consolidara como una potencia internacional de tamaño medio que ejerce una considerable influencia política y económica en áreas como América Latina y el Mediterráneo $^{8}$.

Aún cuando la integración en Europa fuera la prioridad de los Gobiernos de la transición, especialmente del socialista, la política exterior española no se agotaba en esta dimensión ${ }^{9}$. La integración en Europa se compatibilizaría con la adhesión a otras estructuras occidentales de seguridad, la OTAN y la UEO, el compromiso con otros marcos multilaterales como el régimen de no proliferación o la Conferencia de Seguridad y Cooperación en el

\footnotetext{
${ }^{7}$ En el marco jurídico anterior al Tratado de Lisboa, la Presidencia fijaba la agenda de la PESC al liderar el Consejo Europeo y el Consejo de Asuntos Exteriores, asumía la representación de la Unión, era responsable de la ejecución de las decisiones PESC y de expresar la posición de la Unión en las organizaciones y conferencias internacionales. Véase el antiguo artículo 18 del Tratado de la Unión Europea.

${ }^{8}$ En relación al desarrollo de España como potencia media del sistema internacional y la influencia de la integración europea en este proceso, véase: Balfour, Sebastián y Quiroga, Alejandro (2007): The Reinvention of Spain: nation and identity since democracy, Oxford, Oxford University Press, pp. 161-196; Gillespie, Richard y Youngs, Richard (eds.) (2001): Spain: the European and international challenges, Abingdon, Routledge; Pereira, Juan Carlos (co.) (2010): La política exterior de España, (2 ed.), Barcelona, Ariel.

${ }^{9}$ En este sentido pueden citarse las palabras del que fuera Ministro de Asuntos Exteriores en el primer Gobierno socialista, Fernando Morán: "La integración de España en la Comunidad no nos libera de la búsqueda de un orden internacional más justo y estable ni nos cubre frente a situaciones propias; tampoco tiene por qué eliminar otras dimensiones de nuestra política. España pesará en la medida en que posea una política bien pensada, razonable, pero no voluntariamente capitidisminuida”. Morán, Fernando (1980): Una política exterior para España, Barcelona, Planeta, p. 350.
} 
Mediterráneo e, incluso, labores de mediación internacional en Centroamérica ${ }^{10}$. España continuaría con su agenda multilateral en el seno de las Naciones Unidas, que le llevaría a participar en numerosas Operaciones de Paz desde comienzos de la década de los noventa.

Al margen de la política europea de España, nuestro país proseguiría con independencia otra política de influencia en áreas con las que se tienen vínculos históricos y culturales, como es el caso de Iberoamérica. En este sentido, en 1991, esto es, en el mismo momento en que se inicia el debate sobre la PESC, España lanzaría la iniciativa de la Conferencia Iberoamericana, marco de cooperación multilateral con las antiguas colonias, asociando a Portugal y su área de influencia. Desde ese momento la cooperación iberoamericana se entendería como una vía paralela y no incompatible con el desarrollo de una política europea en la zona ${ }^{11}$.

Llegados a este punto, existen relevantes estudios sobre la influencia mutua de la integración y la política exterior europea en la política exterior española y, viceversa, el papel de España en la política exterior europea, en lo que se ha considerado una europeización ${ }^{12}$. En primer lugar, examinaremos los efectos sobre la política exterior española de la integración y la pertenencia a la CEE/UE en una perspectiva que podríamos calificar de top-down:

a) La participación en la integración europea ha sido utilizada por parte de los sucesivos Gobiernos de forma instrumental, lo que ha permitido una modernización de nuestra política exterior y el incremento de nuestro peso internacional $^{13}$. España ha podido reforzar sus capacidades diplomáticas, mejorar su prestigio internacional, definir mejor sus intereses nacionales, superar una agenda exterior tradicionalmente complicada e, incluso, destinar más recursos para ganar en eficacia.

b) Íntimamente ligado con lo anterior, la estructura ejecutiva y administrativa española se ha socializado, adquiriendo un perfil proeuropeo y europeizado. En este sentido, la élite diplomática que negocia y aplica los acuerdos europeos se encuentra dispuesta a admitir las normas europeas y a adecuar su comportamiento a los nuevos estándares ${ }^{14}$. Es preciso subrayar la relevante transformación de las

\footnotetext{
${ }^{10}$ Véase, entre otros: Rodríguez Mojón, Marisa (1993): "The impact of EC membership on Spanish foreign policy", en: Almarcha Barbado, Amparo (ed.): Spain and EC Membership Evaluated, New York, St Martin's Press, pp. 99-102; Benavides, Pablo (1991): "Política Exterior Española y Cooperación Política Europea”, CEE News, $\mathrm{n}^{\mathbf{0}} 75$, pp. 11-20.

${ }^{11}$ En relación a la cooperación iberoamericana, véase: Del Arenal, Celestino (Co.) (2005): Las Cumbres Iberoamericanas (1991-2005): Logros y desafíos, Madrid, Siglo XXI. En otro lugar hemos estudiado la compatibilidad de los marcos de la Asociación Eurolatinoamericana y la Cooperación Iberoamericana: Guinea Llorente, Mercedes, “"La Comunidad Iberoamericana como instrumento para la construcción del Espacio Eurolatinoamericano", en: Aldecoa Luzárraga, Francisco y Sobrino Heredia, José Manuel (Co.) (2007): Migraciones y desarrollo. II Jornadas Iberoamericanas de Estudios Internacionales, Montevideo 25, 26 y 27 de octubre de 2006, Madrid, Marcial Pons, pp. 181-194.

${ }^{12}$ Véase entre otros, Barbé, Esther (1999): La política europea de España, Barcelona, Ariel; Closa Carlos y Haywood, Paul M. (2004): Spain and the European Union, Basingstoke, Palgrave-Macmillan; Torreblanca, Ignacio (2001), "La europeización de la política exterior española”, en: Closa, Carlos (ed.): La europeización del sistema político español, Madrid, Istmo, pp. 486-511; Sabá, K. (1996): "Spain: Evolving foreign policy structures- From EPC Challenge to CFSP management", en: Algieri, Franco y Regelsberger, Elfriede (eds.): Synergy at work. Spain and Portugal in European foreign policy, Bonn, Europa Verlag, pp. 181-206.

${ }^{13}$ Closa y Heywood, op. cit., pp. 215-216.

${ }^{14}$ Barbé, Esther (2011): "Spain and Europe. Mutual reinforcement in foreign policy", en: Wong Reuben y Hill, Christopher, National and European Foreign Policies. Towards Europeanization, Abingdon, Routledge, pp. 131-148, esp. las pp. 132 y 133.
} 
Fuerzas Armadas españolas y de otras fuerzas de seguridad consecuencia de su inserción en fuerzas multinacionales europeas y participación en Operaciones Petersberg, derivadas del marco $\mathrm{UE}^{15}$.

c) Se ha producido también un fenómeno que podríamos calificar de importación de preferencias y políticas de nuestros socios europeos y de la propia UE cuando surge como cuerpo político. La definición de preferencias e intereses españoles cambia como consecuencia de un proceso de convergencia causado por el surgimiento de una identidad colectiva, por la existencia de intereses comunes y la percepción de la imposibilidad de afrontar esos intereses de forma bilateral ${ }^{16}$. Surgen así áreas de interés político nuevas, como por ejemplo, Europa del Este o los Balcanes. Se produce una multilateralización en las estrategias españolas, mientras que se abandona el tradicional bilateralismo. Aparecen nuevos intereses de política exterior derivados de la participación en la integración como el comercio internacional, el sistema monetario internacional, el cambio climático, la seguridad internacional, etc. Se impone también un nuevo ethos o marco de valores de la política exterior, como la promoción de los derechos humanos y la democracia o la cooperación para el desarrollo, que asume la política exterior española.

En la segunda dimensión de la europeización puede considerarse el segundo flujo de influencia, la contribución de España, quinto país en tamaño de la UE, a la política exterior europea, en un enfoque que sería bottom-up:

a) En el plano constitucional, España ha sido tradicionalmente un Estado miembro favorable y activo con el desarrollo tanto con la dimensión política de la integración como con el instrumento de una política exterior europea. Dado que la integración europea le permite alcanzar una dimensión política que no tenía antes, los sucesivos Gobiernos españoles han considerado tradicionalmente que la defensa de sus intereses nacionales pasa por el desarrollo político de Europa y su consolidación como actor global ${ }^{17}$. Esto le ha llevado a apoyar incondicionalmente las iniciativas políticas de dotar a la UE con instrumentos de política exterior, la creación y el desarrollo de la PESC en Maastricht y Ámsterdam, la posterior puesta en marcha de la PESD tras Saint-Malo y la profundización de ambas en la Convención Europea ${ }^{18}$. En una posición que se califica de ambigua, a pesar de que España se ha presentado tradicionalmente como federalista, en el caso de la PESC siempre ha defendido su carácter

\footnotetext{
${ }^{15}$ Desde los años noventa, España toma parte en fuerzas multinacionales europeas de diversas formas. Pueden citarse el Eurocuerpo, Eurofor, Euromarfor, la Fuerza Anfibia Hispano-italiana, el Grupo Aéreo Europeo o más recientemente la Iniciativa Anfibia Europea o la Fuerza de Gendarmería Europea. Véase al respecto: Sanz Román, José Manuel (2010), "España y las fuerzas multinacionales europeas. Perspectivas de futuro", en: "El futuro de las fuerzas multinacionales europeas en el marco de la nueva Política de Seguridad y Defensa", Centro Superior de Estudios de la Defensa Nacional, Documentos de Seguridad y Defensa, no 33 (Mayo 2010).

${ }_{16}$ Torreblanca, op. cit., p. 486.

${ }^{17}$ Como veremos más adelante, esta afirmación podría matizarse en el caso del segundo Gobierno de José María Aznar, de 2000 a 2004, que constituye una excepción a la regla general de estos veinticinco años de pertenencia a la UE.

${ }^{18}$ Véase al respecto: Palomares, Gustavo: "La europeización de la política exterior y de seguridad en el marco de la Unión Europea”, en: Pereira, op. cit., pp. 395-416.
} 
intergubernamental y la decisión por consenso ${ }^{19}$. Se apoya la política común, pero se trata de proteger el interés nacional. En el plano de la seguridad, tradicionalmente España ha sido proclive al desarrollo de una identidad europea de defensa compatible con la estructura occidental de la OTAN.

b) En lo relativo a la exportación de prioridades y políticas, España ha sido capaz de hacer que la UE se implique y formule políticas globales hacia dos de sus principales áreas de interés, el Mediterráneo, incluyendo el conflicto de Oriente Medio, y América Latina, con diferente éxito y alcance ${ }^{20}$. España ha conseguido así la europeización de dos de sus políticas bilaterales fundamentales, la primera causada por razones de seguridad, la segunda de prestigio ${ }^{21}$. En ambos casos se ha conseguido un amplio respaldo político y recursos financieros para unas estrategias y unas políticas diseñadas fundamentalmente desde las prioridades y los intereses españoles ${ }^{22}$. La multilateralización de estas políticas bilaterales ha permitido, indudablemente, el reforzamiento del perfil internacional de la UE y de la propia España en el mundo. Como activos de política exterior también ha contribuido a fortalecer la posición de la propia España en la UE y en sus estructuras de política exterior.

c) En tercer lugar, también puede hablarse de una transferencia de problemas de la política exterior española al plano europeo, que por la masa crítica europea, facilita su tratamiento y, en ocasiones, su resolución ${ }^{23}$. En este aspecto, la política mediterránea puede considerarse también en su dimensión de transferencia de problemas, en la medida en que pretendía entre otros aspectos la solución de los diferentes contenciosos bilaterales con Marruecos. Si bien algunos de ellos pueden considerarse diluidos por la acción del marco europeo (pesca, comercio agrícola), otros como el Sáhara Occidental o Ceuta y Melilla persisten ${ }^{24}$.

Siguiendo este marco de análisis de la influencia bidireccional de la UE en la política exterior española y España en la Política Común Europea, plantearemos ahora el análisis de los diez últimos años.

\footnotetext{
${ }^{19}$ Closa y Heywood, op. cit., p. 229.

${ }^{20}$ Esta cuestión ha sido profusamente tratada por los autores, desde diferentes puntos de vista. Véanse entre otros: Aldecoa (2007), op. cit.; Barbé (1999), op. cit.; Closa y Heywood, op. cit., pp. 220-229; Torreblanca, op.cit., pp. 486-489.

21 Barbé, Esther: "De la ingenuidad al pragmatismo: 10 años de participación española en la máquina diplomática europea”, Affers internacionals, no 34-35, (1996), pp. 9-29.

${ }^{22}$ Closa y Heywood, op. cit., p. 220.

${ }^{23}$ Tomamos este concepto de Torreblanca, a pesar de que él le da un contenido más amplio para abarcar la categoría anterior de exportación de políticas. Torreblanca, op.cit., p. 486

${ }^{24}$ Hace ya quince años Barbé sostenía que España -el Gobierno de Felipe González- se escudaba en la posición europea para obviar sus responsabilidades en el caso del Sáhara, tratar de tomar una posición equidistante entre las partes y trasladar el problema a las Naciones Unidas. Creo que hoy más que nunca se puede constatar lo acertado de esa conclusión, en que la política europea y la necesidad de concertarse con otros socios sirve a España de excusa perfecta para no tomar un papel activo en la defensa de los derechos del pueblo saharaui, que, por otra parte, le granjearía problemas en su relación con Marruecos. Véase: Barbé (1996), op. cit., p. 15.
} 


\section{España y la Política Exterior Común en el segundo Gobierno de Aznar (2001-2004)}

En estos diez años la posición española respecto a la PESC ha coincidido con la concepción de la UE que tuviera el Gobierno de turno. La década comenzó con el segundo Gobierno de Aznar (2000-2004), que tenía una visión intergubernamental de la integración europea, que se vio reforzada por los acontecimientos exteriores, especialmente el 11 de Septiembre y la Guerra de Irak. En el año 2003 se produjo el mayor alejamiento de la política exterior española del núcleo duro no sólo de la PESC sino de la UE. Al desencuentro por la conveniencia de atacar Irak hubo que unir el bloqueo por parte española de la Conferencia Intergubernamental de 2003 de la cual se esperaba que adoptara el Tratado Constitucional. Sin embargo, el Gobierno español había aceptado de buena gana el conjunto de propuestas de profundización de la PESC y la nueva dimensión de la Política Común de Seguridad y Defensa.

\subsection{El contexto internacional y europeo y la posición de España en Europa y en el mundo}

La década de los años 2000 arrancaba con un acontecimiento que traería consecuencias fundamentales para la agenda internacional de seguridad y la política exterior de todos los Gobiernos occidentales: los ataques terroristas del 11 de Septiembre en Nueva York y Washington. La percepción de vulnerabilidad creciente tendría importantes consecuencias directas en los años siguientes, desde la necesidad de dotar a la UE de nuevos instrumentos de acción internacional y la puesta en marcha de la Convención Europea, a la consideración de la cooperación antiterrorista como elemento de la política exterior, o el lanzamiento de acciones armadas en Afganistán e Irak. El 11-S tuvo relevantes connotaciones para la política exterior del segundo Gobierno de Aznar, que ya con mayoría absoluta tenía una agenda más tranquila en casa, lo que le permitiría concentrarse en la dimensión exterior. El contexto internacional resultaría muy favorable a la prioridad española de la inserción de los temas relativos a la lucha antiterrorista en la agenda internacional y europea.

En el plano de la Unión Europea los años que van del 2001 al 2004 van a estar prácticamente centrados en dos procesos de mutación paralelos ${ }^{25}$. En primer lugar, es preciso citar la gran ampliación al Centro y Este de Europa que viviría su primera oleada en mayo de 2004, incrementando el número de Estados miembros de 15 a 25. La ampliación tendría consecuencias directas para la política exterior española, que veía como una amenaza la traslación del centro de Europa hacia el Este y la posibilidad de que sus prioridades en política exterior se vieran por tanto desplazadas. Se sostiene, en cualquier caso, que España ha comenzado a defender su interés nacional abiertamente en la política exterior europea en el momento en que la ampliación al Este ha sentado la percepción de que nuestro país podía quedar marginado dentro de la $\mathrm{UE}^{26}$. El segundo proceso de mutación -profundizacióndemocratización- que dio comienzo en el año 2001 fue el de la gran reforma europea, a través de una Convención, que tras un complicado proceso de aprobación y ratificación no ha llegado a entrar en vigor hasta el 1 de diciembre de $2009^{27}$. Resultará, por tanto, fundamental

\footnotetext{
${ }^{25}$ En relación a los vectores de mutación, véase: Aldecoa Luzárraga, Francisco (2002), op. cit., pp. 50-55.

${ }^{26}$ Barbé (2011), "Spain and Europe...", op. cit., p. 131.

${ }^{27}$ En relación a la reforma constitucional que desemboca en el vigente Tratado de Lisboa, véase: Guinea Llorente Mercedes (2011): La génesis del Tratado de Lisboa: la Convención Europea, Madrid, Congreso de los Diputados.
} 
examinar el papel de España en esta reforma, que se inició bajo Presidencia española precisamente.

La concepción del papel de España en la UE y en el mundo de Aznar difería notablemente de la que había caracterizado la política exterior de los sucesivos Gobiernos de González. Se pasa del europeísmo como referente de la política exterior española al atlantismo. Se abandona el idealismo europeísta y el apoyo sin crítica a la integración europea que se fundamentaba en la idea de que el fortalecimiento de la Unión Europea en la senda federal es siempre y en todo caso positivo para España. Aznar, por el contrario, defenderá desde el principio un mayor pragmatismo: "Entre euroentusiasmos indiscriminados y euroescepticismos extremos, yo me inclino a pensar que nuestra posición en Europa no necesita un replanteamiento, pero sí una actuación, por así decirlo, permanente, vigilante, más firme en la defensa de intereses nacionales concretos" 28 . En esta idea se desliga ya la asunción previa de que el interés español sea automáticamente coincidente con el interés europeo. Ahonda más esta idea considerando que es preciso reflexionar sobre el futuro de España en el marco europeo y anuncia una vigilancia estrecha de los procesos de ampliación y profundización. "España ha de aspirar a que estos procesos beneficien su propia posición internacional y de los intereses concretos de sus ciudadanos" 29 .

Igualmente, insistiendo en la categoría de España como potencia media se subraya que sus intereses deben llevarle a perseguirlos a través de otros instrumentos diferentes que los europeos, por la vía bilateral. "España es Europa, pero no sólo es Europa"30. España para él, octavo potencia económica del planeta, tenía dimensión suficiente para desarrollar una política exterior propia y no tener que depender de lo que decidiera el núcleo de la UE, el eje francoalemán. En su agenda internacional, Aznar impulsaría las relaciones bilaterales españolas en paralelo con la agenda europea ${ }^{31}$. Priorizaría especialmente una relación privilegiada con Estados Unidos, reforzada por su afinidad personal con Bush y por la posición especial que tendría temporalmente España en el Consejo de Seguridad de Naciones Unidas en los años 2003-2004. En un primer momento, trataría de acercar a la UE y a Estados Unidos, como se ve en el Programa de la Presidencia de $2002^{32}$.

El paralelo proceso de acercamiento a Estados Unidos y alejamiento de Francia se vería además impulsado por las difíciles relaciones de España con Marruecos, que venían de atrás y que llegan a su momento álgido con la invasión marroquí del islote Perejil en el verano de 2002. La posición francesa de apoyo a Marruecos inhibió una posición europea de apoyo a España, lo que hizo que España solicitara la mediación estadounidense para zanjar el conflicto, lo que se logró a través del Secretario de Estado Powell.

En el momento álgido del conflicto político previo a la Guerra de Irak, España sería el principal valedor de las tesis estadounidenses dentro de la UE, o como se dijo en la época, el líder de la Nueva Europa ${ }^{33}$. La presencia de Aznar en la Cumbre de las Azores le llevaría a un

\footnotetext{
${ }^{28}$ Aznar, José María (1996): "Presente y futuro de España en el mundo", Ensayos INCIPE, nº 8, Madrid, Instituto de Cuestiones Internacionales y Política Exterior.

${ }^{29}$ Ibid.

${ }^{30}$ Ibid.

${ }^{31}$ En esta época se promovería la inversión española en América Latina y el posicionamiento español en sectores estratégicos latinoamericanos. Es la llamada "diplomacia de los negocios".

${ }^{32}$ Véase en ese sentido: Presidencia española de la UE (2001): "Más Europa" Programa de la Presidencia española de la UE, Madrid, BOE.

${ }^{33}$ En este sentido, antes de la participación con Blair, Bush y Barroso en la Cumbre de las Azores hay que recordar que Aznar fue el promotor y uno de los firmantes de la llamada "Carta de los Ocho", publicada en varios diarios europeos en la que se defendía la intervención en Irak. Aznar, José María; Durao-Barroso, Jose
} 
alejamiento completo de Francia y Alemania, con repercusiones en toda la política europea e, incluso, en el bloqueo de la Conferencia Intergubernamental de diciembre de $2003^{34}$. La opción atlantista de Aznar tendría una doble consecuencia: la reducción de su capacidad negociadora en el marco de la UE y el progresivo alejamiento de la opinión pública española por la política exterior de Aznar ${ }^{35}$.

El proyecto europeo de Aznar, por tanto, puede recibir cuatro adjetivos. Intergubernamental, al ser partidario de una Europa de los Estados más que de un proyecto federal o, incluso, funcionalista. Economicista, ya que prima las ventajas de una integración económica inspirada en el liberalismo anglosajón sobre el compromiso con la construcción política. Utilitarista, en el sentido de que apoya caso por caso las iniciativas que benefician al interés nacional antes que el proyecto político en sí, es decir, veía en la UE más un instrumento que un fin en sí mismo ${ }^{36}$. Y no excluyente, al entender que la pertenencia a la UE no tiene por qué obstaculizar las relaciones bilaterales españolas. Esto llevó a que España como Estado miembro abandonara la alianza estable con los países más integracionistas -el eje francoalemán y el BENELUX especialmente- para aliarse con los que defendían un modelo económico e intergubernamental, sobre todo el Reino Unido y la Italia de entonces ${ }^{37}$. Estas afinidades se verían reforzadas por la cuestión de la Guerra de Irak en febrero de 2003, momento en que se rompe el tradicional respeto español de las posiciones comunes acordadas en el seno de la PESC ${ }^{38}$. Desde el Gobierno español se priorizó sobre todo la relación transatlántica bilateral antes que la concertación con los demás socios europeos en la PESC. Esta misma posición junto a la defensa de Niza le va a llevar a que, a partir de 2003, se tejan también una estrecha alianza con Polonia, que se adheriría en 2004.

\subsection{España en la PESC y la PESC de España}

Tras esta visión general de la posición del Gobierno español ante la Unión Europea y su papel en el mundo cabe analizar detalladamente las dos direcciones de influencia de la política exterior española y la política exterior europea, siguiendo el modelo trazado antes. Dada la

Manuel; Berlusconi, Silvio; Blair, Toni; Medgyessy, Peter; Miller, Leszek; Rasmussen, Anders Fogh y Havel, Vaclav: "Europa y América deben permanecer unidas", El País, 30 de enero de 2003. La división entre la Nueva y Vieja Europa al entonces Vicepresidente estadounidense Cheney y haría referencia a sus aliados, mayoritariamente países que se iban a adherir, y los contrarios a la intervención en Irak, unidos en torno a Francia y Alemania.

${ }^{34}$ Véase: Aznar, José María, Blair, Tony y Bush, George: Declaración de las Azores, 16 de marzo de 2003.

${ }^{35}$ Barbé, Esther (2003): "La política europea de España 2002-2003”, Observatorio Europeo de Política Exterior Europea, Instituto Universitario de Estudios Europeos, Working Paper, no 48 (2003), Universidad Autónoma de Barcelona, p. 5.

36 Barbé estima con acierto que la característica de la política europea de Aznar fue "convertir sus preocupaciones domésticas en factor exclusivo de su estrategia europea, con independencia del contexto de cada momento y de la necesidad de encajar objetivos nacionales con objetivos europeos". Barbé Esther, "Pensar diferente, actuar en Europa", en: Barbé, Esther (co.) (2008): España en Europa 2004-2008, Barcelona, Universidad Autónoma de Barcelona, Instituto Universitario de Estudios Europeos, p. 1.

${ }^{37}$ En este sentido y como ejemplo del proyecto aznarista de integración europea es preciso citar la llamada Agenda de Lisboa, lanzada en el Consejo Europeo del mismo nombre de marzo de 2000. La Agenda fue impulsada por la acción concertada de Blair, Berlusconi, Aznar y Guterres y se proponía impulsar la competitividad de la economía europea para el año 2010 a través del método de concertación abierta que no supone cesión de competencias al modo comunitario sino mera coordinación intergubernamental apoyada por el "peer-review". Véase al respecto: Consejo Europeo (2000): Conclusiones de la Presidencia, Lisboa.

${ }^{38}$ La Declaración de las Azores y el posterior apoyo a la intervención en Irak contravienen literalmente los términos de sucesivas Resoluciones del Consejo, donde se llamaba a la negociación y a la resolución pacífica del conflicto dejando actuar a las Naciones Unidas y que habían sido sucesivamente suscritas por España. La última de ellas fue la Resolución del Consejo de Relaciones Exteriores de 27 de enero de 2003. Véase: Consejo de Relaciones Exteriores, Sesión nº 1482 del Consejo, 27 de enero de 2003, (5396/03), p. 14. 
posición menos comprometida de Aznar ante la política exterior europea, cabe lógicamente preguntarse si puede hablarse de algún tipo de repercusión de la política exterior europea en la española. En sentido contrario, examinaremos también la promoción de intereses españoles a través del marco de la política exterior común de la Unión Europea.

Se puede avanzar que, en este periodo, la política exterior española ha ido en buena parte en paralelo con la europea, salvo una excepción relevante, la relativa a Irak que ya se ha comentado. En este sentido, en marzo de 2003, al suscribir la Declaración de las Azores el Gobierno español iría contra su obligación de lealtad y solidaridad política con la PESC, al abandonar las líneas de las resoluciones aprobadas por el Consejo con anterioridad. Salvo esta divergencia sustancial y en la cual tampoco estuvo sólo, cabe apreciar que la política exterior española siguió la senda de la europea.

\subsection{1. ¿Europeización de la política exterior española?}

España tradicionalmente ha sido uno de los Estados miembros más proclives al desarrollo de una dimensión política de la acción común europea y aliado firme con el eje francoalemán para el desarrollo de la PESC. No sólo ha defendido CIG tras CIG los enfoques más integracionistas, sino que se ha mostrado tradicionalmente respetuoso de los acuerdos PESC y cumplidor de las normas acordadas en su seno. Es decir, España como Estado voluntariamente aceptaba la europeización de su política exterior, incorporando el contenido de la PESC en su política.

Si el talante de Aznar era menos comprometido con el desarrollo y el respeto de la política común acordada en el seno de la UE, ¿puede detectarse algún grado de europeización en este periodo de la política exterior española? En el primer sentido, como reflexión previa, es preciso sostener que la posición reforzada de España en la estructura internacional a comienzos de los 2000 es deudora de su pertenencia a la UE y, especialmente, del desarrollo político y económico que ha logrado en su seno. España se convierte en potencia media gracias a su europeización. Además, puede defenderse, sin lugar a dudas, que el hecho de que Aznar y su Gobierno recibieran especial atención de Bush era especialmente debido a su pertenencia a la UE, además del hecho coyuntural de sentarse en el Consejo de Seguridad. Bush buscó en Aznar la punta de lanza dentro de la UE que, junto a socios tradicionales como el Reino Unido, le permitiera convencer a los otros Estados miembros de la conveniencia de apoyar su proyecto para Irak.

En el segundo plano, la europeización de los responsables españoles de la política exterior también continuó como consecuencia del trabajo diario entre burocracias. Conviene subrayar, además, que en su mayoría la élite diplomática española ya muy europeizada se sintió incómoda con las políticas de Aznar en relación a la Unión, a la ruptura con los tradicionales aliados y al vínculo transatlántico ${ }^{39}$. En esta etapa, además, en que comienza el desarrollo de las estructuras PESD así como la primera de las Operaciones Petersberg en 2003 puede detectarse el comienzo de la europeización de los miembros de las fuerzas armadas implicados y un avance relevante en la reestructuración de las mismas ${ }^{40}$. Se continúa así con la senda de la europeización iniciada por la colaboración española en fuerzas multinacionales europeas puestas en marcha en los años noventa.

\footnotetext{
${ }^{39}$ Barbé, Esther (2011), "Spain and Europe...", op. cit., p. 133.

${ }^{40}$ Realmente la reestructuración de las fuerzas armadas españolas había comenzado en la primera década de los 90 como consecuencia de la participación española en misiones de paz de Naciones Unidas en América Central y el Sur de África.
} 
En tercer lugar, respecto a la importación de políticas europeas que sean incorporadas a la agenda española, supone el caso más relevante de europeización la pronta asociación de España al desarrollo de la PESD asumido por los dos Estados miembros con capacidad relevante, Reino Unido y Francia en la Cumbre de Saint-Malo de mayo de 1998. España se incluye entre los países que apoyan una identidad europea de defensa, ya que en este caso convergen las necesidades españolas con la profundización del proceso de integración ${ }^{41}$. A pesar de que no posee ni capacidades reseñables ni una financiación destacada, el apoyo español resultará relevante para la PESD por tratarse de uno de los Estados grandes y que más constancia han mostrado en el apoyo y participación en las misiones europeas de gestión de crisis. Esa europeización se constata en la aprobación de dos importantes documentos estratégicos, el Libro Blanco de Defensa (2000) y la Revisión Estratégica de la Defensa (2003), que asumen el compromiso con el desarrollo de una capacidad de defensa autónoma por parte de la UE capaz de desarrollar misiones de gestión de crisis ${ }^{42}$. Por su parte, Aznar defenderá la idea de vincular la PESD a la OTAN, con estructuras de refuerzo mutuo y objetivos compatibles.

En paralelo al apoyo al desarrollo de la PESD, España participará en las primeras misiones de gestión de crisis desarrolladas por la UE. Tomará parte tanto en las misiones civiles EUPM en Bosnia-Herzegovina, como en Proxima, desarrollada en Macedonia. También contribuirá con efectivos y capacidades a las primeras operaciones militares de la UE en los Balcanes, desarrolladas en el marco del acuerdo Berlín Plus con la OTAN. Se trata de la operación Concordia en Macedonia y de la decisión de participar en la EUFOR-Althea en Bosnia, decisión que ya le tocaría ejecutar al Gobierno socialista.

Consecuencia de la europeización top-down, España en esta época participa en una serie de acciones y políticas que no proceden de sus intereses tradicionales, sino de los compromisos que ha adquirido como consecuencia de su pertenencia a la Unión y otras estructuras internacionales como la OTAN ${ }^{43}$. Comienza así a implicarse en una política europea activa hacia la resolución de los conflictos y la reconstrucción de los Balcanes, lo que le lleva a participar incluso en las primeras misiones de gestión de crisis desarrolladas en este escenario. En relación a la política con Rusia, con quien no tiene gran relación, España ha tendido a asociarse a la posición pragmática de los poderes centrales como Francia, Alemania e Italia, que evita disgustar al Kremlin y buscar vías de cooperación. Es una tendencia que hoy día se sigue, reforzada por que en la actualidad los intereses energéticos son mayores.

Sosteníamos con anterioridad que aún cuando la CE/UE fuera el marco de referencia para la política exterior europea, incluso los Gobiernos más europeístas optaban por seguir una vía bilateral o multilateral propia. En el caso del Gobierno de Aznar, su visión utilitarista del proyecto europeo incrementa la independencia de la política exterior española, como se pone de relieve en las relaciones especiales con Bush y el desarrollo de tesis propias en el marco de Naciones Unidas. Esta época que coincide con el florecimiento económico de España conducirá también a que Aznar solicite su inclusión en el G-8 como consecuencia del peso de la economía española en el mundo. Igualmente se impulsaría la cooperación iberoamericana a través de la institucionalización, primero con la creación de la Secretaría de Cooperación Iberoamericana en 1999 y, posteriormente, su conversión en la Secretaría

\footnotetext{
${ }^{41}$ Barbé, Esther (2011), "Spain and Europe...”, op. cit., p. 134.

${ }^{42}$ Maria A. Sabiote: "España y las operaciones de gestión de crisis de la Unión Europea: buscando un lugar en la Europa de la Defensa”, en: Barbé, Esther (co.) (2008), op. cit., pp. 75-81.

${ }^{43}$ En este sentido, además de la especial sintonía con Estados Unidos hay que ver la implicación española en la operación ISAF liderada por la OTAN en Afganistán, que no es un caso de europeización sino de "occidentalización".
} 
General Iberoamericana en 2003 con la función de coordinar y dar seguimiento al conjunto de la cooperación iberoamericana.

\subsubsection{La influencia de España en la Política Exterior Común: áreas de interés y problemas}

La influencia de abajo a arriba de España en la Política Exterior Común puede trazarse en relación a la triple división que veíamos más arriba. En el plano constitucional, la falta de compromiso con el proyecto político federalista de Aznar no impidió en las Conferencias Intergubernamentales de Ámsterdam y Niza su apoyo deliberado a la profundización de la PESC y la PESD. Una Europa fuerte en el exterior convenía a los intereses españoles y a una mayor dimensión de España en el mundo. Además, su carácter intergubernamental no afectaba a la soberanía nacional y se adecuaba perfectamente a la concepción aznarista de la integración como cooperación. En la CIG de Niza se apoyará desde España también la profundización de los instrumentos de la PESD y la flexibilidad en la política exterior.

El final del Gobierno de Aznar coincidirá con los trabajos de la Convención Europea y la CIG de 2003, llamada a aprobar el Tratado Constitucional que la Convención elaboró. El fracaso de la CIG en diciembre de 2003 fue achacable a España y Polonia que se aliaron para bloquear el acuerdo por una doble razón, la defensa del mecanismo de votación del Consejo pactado en el Tratado de Niza y la mención al papel del cristianismo en Europa en el Preámbulo de la Constitución. A pesar de todo ello, la posición española sería ambiciosa en el ámbito de las reformas: apoyaría la creación del Presidente del Consejo Europeo, la del Ministro de Asuntos Exteriores y del Servicio Europeo de Acción Exterior con doble sombrero, la extensión de la mayoría cualificada en la PESC, las cooperaciones estructuradas en la PESD, la inclusión del terrorismo en las Operaciones Petersberg y la posibilidad de activar la cláusula de solidaridad en caso de ataque terrorista. Se respaldaría la profunda reforma constitucional de la PESC y la PESD, que se ha trasladado íntegra al Tratado de Lisboa y que en algunos de los casos saldría incluso de su iniciativa política ${ }^{44}$.

La exportación de las áreas especiales de interés político para España continuaría en esta etapa, manteniéndose el impulso de la política latinoamericana y la mediterránea. En el ámbito latinoamericano, sin que existiera más iniciativa en la parte europea, España monopolizó las llamadas de atención de los europeos hacia esta zona con la preocupación de que la ampliación al Este hiciera perder interés y recursos para América Latina. Además de la intención de refundación que tendría la Cumbre de Madrid, España utilizó con eficacia el amplificador europeo para dar mayor eficacia a su posición en la zona. Como ejemplo de este extremo cabe citar el impulso español a la adopción de una Posición Común hacia Cuba que condicionara la cooperación a la apertura del régimen de Castro. También cabe subrayar un giro en el contenido de la política española que va a dar mayor relevancia en la relación mutua a la cooperación económica en general y a las inversiones.

En el ámbito de la política euromediterránea, España no ha podido ejercer un liderazgo en solitario como en el caso anterior, sino que choca con los intereses franceses en la política europea. Se producían dos tendencias opuestas. Por una parte, el conflicto creciente con Marruecos, primero por cuestiones pesqueras y después territoriales, impedía la posibilidad de un liderazgo español. Este, sin embargo, sería mejor recibido en el caso del conflicto de Oriente Medio, donde se impulsaron posturas tendentes a la mediación europea en el Proceso de Paz. El desarrollo de un especial vínculo transatlántico entre Europa y América (Estados

\footnotetext{
${ }^{44}$ Así puede recordarse cómo la iniciativa de dotar al Consejo Europeo con un Presidente permanente que asumiera entre otras funciones la representación exterior de la Unión surge de una propuesta conjunta de Aznar, Blair y Chirac, por lo que sería conocida como la propuesta $\mathrm{ABC}$.
} 
Unidos) puede considerarse un intento fallido de transferencia de prioridades españolas a la política europea, ya que Aznar fracasó en convencer al conjunto de socios europeos que apoyaran las tesis del ataque preventivo de Bush.

En relación a la transferencia de problemas, el más evidente no es otro que la lucha contra el terrorismo. Los acontecimientos del 11 de Septiembre tuvieron como consecuencia aproximar la agenda mundial de seguridad a la tradicional agenda española de lucha contra el terrorismo de ETA. Aprovechando esta estructura de oportunidad, el Gobierno español logró incorporar esta prioridad no sólo a la política interior de la Unión (cooperación en materia de justicia y asuntos de interior) sino también a los instrumentos de política exterior europea (listas de organizaciones y sanciones PESC, objetivo de la PESD) y a los distintos marcos de relación multilateral europea (relaciones transatlánticas, asociación euromediterránea, relaciones con América Latina y el Caribe $)^{45}$. Se utilizaría especialmente la capacidad de impulso de la Presidencia española para trasladar esta preferencia a la Política Exterior Común europea.

En un segundo término, en estos años España también impulsaría con fuerza una política común europea en materia de inmigración como consecuencia de la problemática que afronta derivada de su carácter de frontera sur de una Unión Europea con libre circulación de personas en su seno. Bajo la Presidencia española se trató de impulsar un plan global de lucha contra la inmigración ilegal, que incluía acuerdos de readmisión con terceros Estados o la gestión común de las fronteras exteriores. Se abordó un tema muy polémico, vincular la cooperación para el desarrollo a la cooperación del país tercero en materia de lucha contra la inmigración ilegal. El Consejo Europeo de Sevilla de junio de 2002 no lograría un acuerdo global, sino avances parciales sobre repatriación coordinada, gestión común de fronteras y un programa de lucha contra el tráfico de seres humanos. La falta de acuerdo global se debió a las diferencias entre Aznar y Chirac, pero sería un tema que volvería con fuerza en los años siguientes a la mesa del Consejo Europeo.

\subsection{La Presidencia española de 2002: "Más Europa"... en el mundo}

La Presidencia del año 2002 tuvo como lema "Más Europa" queriendo reflejar no sólo la intención de reforzar el peso de la UE en el mundo sino también la implicación de los españoles en el proyecto europeo. Bajo Presidencia española se inauguraron los trabajos de la Convención Europea el 28 de febrero de 2002, que iba a adoptar la futura Constitución Europea y donde el reforzamiento de la Política Exterior europea era uno de los temas principales ${ }^{46}$. En el semestre español apenas hubo tiempo para el debate político general de amplios temas. Resulta inútil analizar la contribución de la Presidencia a la profundización de

\footnotetext{
${ }^{45}$ En este sentido, el Consejo Europeo de Sevilla acordaría diversas medidas para incorporar el objetivo de la lucha antiterrorista a todos los ámbitos de la política exterior: refuerzo de la prevención de conflictos, incorporar esta dimensión a todos los acuerdos que se firmen con socios terceros, implementar medidas de cooperación mutua en esta materia, utilización de medios militares en el marco PESD para proteger a la población civil de ataques terroristas, etc. Consejo Europeo (2002), "Declaración del Consejo Europeo sobre la contribución de la PESC, incluida la PESD, en la lucha contra el terrorismo", Conclusiones de la Presidencia, Sevilla, 21 y 22 de junio, Anexo V.

${ }^{46}$ En este sentido la Declaración de Laeken del Consejo Europeo, que recoge la agenda de la Convención, había planteado como uno de los tres objetivos de la reforma afrontar el reto de "el nuevo papel de Europa en un entorno mundializado". Véase: Consejo Europeo (2001), "Declaración sobre el futuro de la Unión Europea", Conclusiones de la Presidencia, 15 de diciembre, Anexo I.
} 
los instrumentos de política exterior, ya que esos trabajos se desarrollarían solo al final del segundo semestre del año ${ }^{47}$.

Una de las prioridades fundamentales de la agenda española era la dimensión exterior de la Unión Europea ${ }^{48}$. Para ello se proponía impulsar las tradicionales áreas de interés españolas como las relaciones con América Latina y con el Mediterráneo pero también se incorporaron nuevas prioridades de la política exterior española como el reforzamiento de las relaciones transatlánticas y el desarrollo de la PESD. Además, la Presidencia española tuvo que gestionar los temas corrientes de la agenda europea, donde no tenía especiales preferencias como Afganistán, las relaciones con Rusia o la política hacia los Balcanes, y se encontró con una crisis sobrevenida en el caso del conflicto de Oriente Medio, que gestionó acertadamente $^{49}$.

Las relaciones con América Latina y el Caribe querían verse relanzadas con la celebración de la II Cumbre Birregional en Madrid. Si bien la cita arrojó algunos resultados en el plano político y de la cooperación, incluyéndose por ejemplo la cooperación en materia antiterrorista entre los objetivos con el apoyo de Colombia, en el plano comercial no se cumplió totalmente la agenda. El objetivo del acuerdo de librecomercio con MERCOSUR se vio imposibilitado tanto por la oposición francesa a abrir los mercados europeos a los productos agrícolas como por la propia crisis argentina. Sin embargo, se concluyó el acuerdo de asociación con Chile y se fijaron las bases de negociación para otro acuerdo bilateral similar con México.

La Cumbre Ministerial Euromediterránea de Valencia supuso un éxito mayor en resultados, a pesar del contexto adverso, con la escalada de la crisis política en Oriente Medio y las diferencias entre los Estados miembros ${ }^{50}$. A pesar de que la Cumbre en sí queda deslucida por la ausencia de destacados líderes, España logró el relanzamiento de las relaciones, con la aprobación de un Plan de Acción. Este Plan incluye un desarrollo de la dimensión institucional de la asociación con propuestas como la Asamblea Parlamentaria Euromediterránea o una Fundación Euromediterránea, que posteriormente recibiría el nombre de Anna Lindh. Igualmente el Plan profundiza la cooperación a través de medidas como una nueva línea de financiación en el marco del Banco Europeo de Inversiones o la participación de los socios en el programa Tempus destinado al desarrollo y modernización de las Universidades de los países vecinos. España lograría también una de sus prioridades, como es incluir la cooperación en materia antiterrorista en la cesta de cooperación en materia de seguridad.

\footnotetext{
${ }^{47}$ Sobre los debates de la Convención, véase: Guinea Llorente (2011), op. cit.

${ }^{48}$ Las prioridades de la Presidencia española de 2002 pueden sintetizarse en tres ejes de profundización del modelo de la UE: la liberalización económica y el desarrollo de la Agenda de Lisboa, la lucha contra el terrorismo -que es a la vez prioridad política interna y externa- y el desarrollo de la política exterior europea. Otras tres prioridades venían dadas por la propia agenda de la Unión: la puesta en circulación del euro, la Convención Europea y el impulso al proceso de ampliación. Véase: Presidencia española de la UE (2001), "Más Europa" Programa de la Presidencia española de la UE - 1 de enero 2002-30 de junio de 2002, Madrid, BOE.

${ }^{49}$ Para un balance detallado de los resultados de la Presidencia española de 2002 en materia de política exterior, véase: Barbé, Esther (co.) (2002): España y la política exterior de la UE: entre las prioridades españolas y los desafíos del contexto, Barcelona, Universidad Autónoma de Barcelona, Instituto Universitario de Estudios Europeos; Powell, Charles: "Un balance de la Presidencia española de la Unión Europea de 2002", Revista de Estudios Políticos, no 119 (2003), pp. 535-561.

${ }^{50}$ Para un análisis detallado de esta cuestión, véase: Montobbio, Manuel: Real Instituto Elcano, "La presidencia española del Consejo de la Unión Europea 2002 y el relanzamiento del proceso de Barcelona”, DT 5/2002 (2002).
} 
Bajo el epígrafe de las relaciones transatlánticas, la Presidencia española se esforzaría por impulsar un marco nuevo de cooperación entre la UE y Estados Unidos, apoyándose en la buena sintonía personal existente entre Aznar y Bush. Bajo la Presidencia española se impulsó la cooperación transatlántica en un ámbito de especial interés para España como era la cooperación en materia antiterrorista, plasmada en la puesta en marcha de negociaciones para un acuerdo sobre extradición y cooperación judicial. Sin embargo, no fue posible profundizar la cooperación en otros ámbitos a causa de las diferencias entre ambas orillas puestas de manifiesto en torno a dossieres internacionales como el Protocolo de Kyoto o el Tribunal Penal Internacional así como por conflictos de tipo comercial en torno al acero y los subsidios a la agricultura.

A lo largo de su Presidencia, España puso especial atención en la cooperación en materia de capacidades que permitiera el lanzamiento de la PESD en el siguiente año. Para ello desde la Presidencia se impulsó un plan de acción de capacidades europeas y ejercicios de gestión de crisis. Tenía también entre sus objetivos el lograr un acuerdo para la coordinación con la OTAN. Este acuerdo no fue posible por las diferencias entre Grecia y Turquía, pero se lograría en los años siguientes. Sí lograría en cambio, como se ha visto, incluir la lucha contra el terrorismo en los objetivos de la PESD en el Consejo Europeo de Sevilla.

En relación al conflicto de Oriente Medio, la Presidencia española había desarrollado algunas propuestas para avanzar en el proceso de paz. Se vio en la necesidad de liderar la respuesta europea ante un agravamiento de la crisis con el cerco a la Iglesia de la Natividad. Contribuiría al alumbramiento en Madrid de una nueva institución que sería fundamental en los años sucesivos, el "Cuarteto", que reúne a la UE con la ONU, Rusia y Estados Unidos para mediar en la solución del conflicto ${ }^{51}$.

A pesar de no ser muy europeísta, el Gobierno de Aznar se volcaría en hacer de la dimensión exterior de la Presidencia europea un éxito. Coincidían, en este caso, los intereses europeos con las ansias españolas y se utilizaba la plataforma europea como un medio para una mayor proyección internacional de España. A los éxitos analizados en el ámbito de las áreas prioritarias para nuestro país, hay que sumar la estrategia de incorporar a todas las dimensiones de la política exterior europea el interés doméstico del Gobierno español de luchar contra el terrorismo.

\section{España y la Política Exterior Común en los Gobiernos de Rodríguez Zapatero (2004-2011)}

El año 2004, caracterizado por el mayor ataque terrorista de la historia española, trajo consigo un cambio de Gobierno a favor del Partido Socialista Obrero Español liderado por Rodríguez Zapatero. Pasaba factura así la ruptura entre la política exterior de Aznar y la opinión pública española. El Gobierno de Zapatero buscará un cambio radical en materia de política exterior y en el papel en la UE en especial. Junto a la retirada de las tropas españolas de la misión de

\footnotetext{
${ }^{51}$ Como consecuencia de la irrupción de la segunda Intifada, se reunieron en octubre de 2001 representantes de la UE, la ONU, Estados Unidos y Rusia con el Presidente palestino Arafat con la finalidad de lograr un alto el fuego y apoyar las reformas solicitadas por la Autoridad Palestina. Durante la escalada del conflicto de abril de 2002, causada por las incursiones israelíes en territorio palestino, los cuatro representantes volvieron a reunirse en Madrid para apoyar el cumplimiento de un arreglo previamente logrado por el Gobierno estadounidense. En esa misma reunión acordaron transformar su cooperación ad-hoc en un foro permanente con la finalidad de promover el proceso de paz en Oriente Medio.
} 
apoyo de Irak y el conflicto con el Gobierno estadounidense de Bush, el Gobierno tomaría entre sus primeras decisiones desbloquear la negociación constitucional europea y volver a la asociación con los países centrales de la UE, Francia y Alemania. España volvía a priorizar el marco de la definición común de la PESC para enmarcar el conjunto de su política exterior, a la vez que se esmeraba progresivamente en recomponer la relación rota con Estados Unidos, lo que no sería posible hasta la llegada al poder de Obama.

La política exterior española y su papel en Europa fueron elementos centrales del debate político de las elecciones de $2004^{52}$. Paradójicamente, ni la una ni el otro serían elementos fuertes del primer Gobierno Zapatero, lo que sorprende especialmente en el caso de la política europea teniendo en cuenta que el Ministro Moratinos venía de desempeñar un cargo institucional en la PESC ${ }^{53}$. Si en su segunda legislatura el Presidente Zapatero afirmaba que daría mayor impulso a la política exterior en su Gobierno, este objetivo se vio pronto malogrado por diversos factores. En primer lugar, la política exterior no es una de las dedicaciones favoritas de Zapatero. Segundo, la irrupción con virulencia en el otoño de 2008 de la crisis financiera haría que la política exterior pasara a un segundo plano. En tercer lugar, como efecto de la ampliación, España perdía peso en Europa y Sarkozy, mucho más activo, terminaba por monopolizar con éxito el liderazgo de la política euromediterránea, eclipsando a nuestro país en esta área tradicional. Por otra parte, la Presidencia española de 2010, que iba a ser el eje del vuelco hacia el exterior, se volvía un ejercicio de gestión del cambio del Tratado de Lisboa, dejando poca posibilidad al impulso político.

\subsection{El contexto internacional y europeo y la posición de España en Europa y en el mundo}

El contexto internacional que se encuentra José Luis Rodríguez Zapatero al acceder al poder no era muy diferente del que le acompañara a Aznar en su segundo mandato. Aún así, la sensación de amenaza que supone el terrorismo internacional se acrecienta al comprobarse que el 11 de Septiembre también puede tener lugar en casa. Sin embargo, la lectura que hacen ambos Presidentes y las políticas desarrolladas no pueden ser más diferentes. Zapatero decide nada más ganar las elecciones cumplir su promesa electoral de retirar las tropas españolas de Irak en abril de $2004^{54}$. Esta medida le valió la enemistad del Gobierno estadounidense, es decir, la ruptura total del vínculo que hasta ese momento había unido a España y Estados Unidos. Esta retirada, unida después a la de Kosovo, tampoco dejaba de pasar factura a la credibilidad internacional del Gobierno español, que daba una imagen de ser poco respetuoso con sus compromisos internacionales. Las relaciones con Estados Unidos no podrían restaurarse hasta el acceso al poder del Presidente demócrata Obama en enero de 2009, a pesar de los diversos intentos del Gobierno de Zapatero.

En 2011 la amenaza terrorista ya no ocupa tanto espacio en los análisis de política internacional, sino que ha sido reemplazada desde 2008 por la mayor crisis internacional que

\footnotetext{
${ }^{52}$ Pueden compararse los dos modelos diferentes que se exponen en los respectivos programas electorales: Partido Popular (2004), “Avanzamos juntos”. Elecciones generales 2004, Programa de Gobierno; Partido Socialista Obrero Español (2004), “Merecemos una España mejor”, Programa Electoral.

${ }^{53}$ Entre 1996 y 2003 Miguel Ángel Moratinos había sido el Representante Especial de la Unión Europea para el Proceso de Paz de Oriente Medio, teniendo su oficina en Chipre.

${ }^{54}$ El 18 de abril de 2004 el recién nombrado Presidente del Gobierno Rodríguez Zapatero anunciaba el regreso de las tropas de Irak fundamentado en su defensa del multilateralismo y la legalidad internacional. Esa retirada se justificaba en el hecho de que no era previsible que el Consejo de Seguridad aprobara una Resolución que traspasase a Naciones Unidas la dirección político-militar de la operación de Irak. Rodríguez Zapatero, José Luis (Presidente del Gobierno), Declaración en relación con las tropas españolas en Irak, Madrid, 18 de abril de 2004.
} 
haya sufrido el capitalismo en su historia ${ }^{55}$. Los temas económicos, monetarios y financieros entran con fuerza en la agenda internacional. Lo que comienza siendo una crisis que afecta a las entidades bancarias como resultado de los bonos basura y el pinchazo de la burbuja inmobiliaria en Estados Unidos, terminaría contagiándose a la economía real por la reducción de la liquidez y la contracción de la demanda. Finalmente en el año 2010 se manifestaría como una crisis de solvencia de los países periféricos del Euro que no son capaces de hallar financiación para unos déficits públicos engordados enormemente por efecto de la crisis. El contexto internacional y la propia agenda europea van a estar condicionados por la necesidad de ofrecer respuestas a una situación que empeora con el tiempo y que pone de manifiesto las limitaciones del diseño de la Unión Económica y Monetaria. Para la política exterior europea esto supondrá la irrupción con fuerza de los asuntos económicos y monetarios en la agenda exterior tanto bilateral como multilateral con el relanzamiento de una institución para la gobernanza de este problema, el G-20 $2{ }^{56}$.

La década de los años 2000 para la UE será la de una profunda mutación e, incluso, de crisis constitucional y de modelo. La llegada de Zapatero al poder coincide con la mayor ampliación de la historia comunitaria que hace que el 1 de mayo de 2004 se incorporen a la UE diez nuevos Estados miembros, a los que se añadirán Bulgaria y Rumanía en 2007. La UE cambia completamente de composición, equilibrios de poder, problemáticas, percepciones, intereses e incluso prioridades de la política exterior. Desde entonces está viviendo un proceso de absorción o adaptación, que puede ser incluso tildado de crisis, que posiblemente aún no haya acabado.

En el plano interno la llegada al poder de Zapatero supondría, de acuerdo con sus ideales, el rápido desbloqueo de la aprobación de la Constitución Europea en junio de $2004^{57}$. No obstante, esta innovación política no llegaría a entrar en vigor como Constitución como consecuencia de los referendos negativos en la ratificación de Francia y los Países Bajos de la primavera de 2005. El hecho de que España hubiera celebrado en febrero un referéndum y que fuera positivo, fue un argumento de peso en los esfuerzos de los más europeístas por sacar adelante la reforma constitucional. Finalmente, los contenidos de la Constitución, que no la forma constitucional, serían incorporados al Derecho Originario europeo a través del Tratado de Lisboa. Este tampoco tuvo una ratificación fácil, tardando dos años más de lo previsto en entrar en vigor, lo que no se produciría hasta el 1 de diciembre de 2009.

En el plano europeo, por tanto, Zapatero va a encontrarse una UE sumida en una profunda crisis de identidad, que no acaba de hallar la salida adelante, y que se debate entre el

\footnotetext{
55 No existe entre los expertos una visión homogénea ni uniforme ni sobre las causas de las distintas crisis encadenadas ni sobre las políticas que los Gobiernos deben promover para salir de ella. Como ejemplo de visiones diferentes puede verse: Krugman, Paul (2009): El retorno de la economía de la depresión y la crisis actual, Barcelona, Crítica; Stiglitz, Joseph E. (2010): Caída libre: el libre mercado y el hundimiento de la economía internacional, Madrid, Taurus; Roubini, Nouriel y Mihm Stephen (2011): Crisis Economics: A Crash Course in the Future of Finance, London; Allen Lane.

${ }^{56}$ El Grupo de los Veinte se puso en marcha en 1999. Reuniendo a los Ministros de Economía y Finanzas y los Gobernadores de los Bancos Centrales de las 19 economías más potentes del mundo (industrializados y emergentes) junto a la Unión Europea, pretendía servir de foro de diálogo para acordar posturas comunes en temas económicos. Desde noviembre de 2008 se reúne en el nivel de Jefes de Estado y de Gobierno y se ha consolidado como el foro internacional clave para abordar la crisis internacional y la reforma de la gobernanza financiera y económica global. Véase al respecto: Bradford, Colin I. y Lim, Wonhyuk (eds.) (2011): Global leadership in transition: making the G-20 more effective and responsive, Washington; Brookings; Jokela, Juha (2011): The G-20: a pathway to effective multilateralism?, Paris, EU Institute of Security Studies.

${ }^{57} \mathrm{Hemos}$ analizado el proceso político que va desde la aprobación de la Constitución Europea, a la imposibilidad de su ratificación y su transformación en Tratado de Lisboa en: Aldecoa, Francisco y Guinea, Mercedes (2010): La Europa que viene: el Tratado de Lisboa, Madrid, Marcial Pons.
} 
compromiso de los Gobiernos por seguir adelante pero una profunda desafección ciudadana. A todo ello, y desde el plano exterior, se sumaría el fracaso europeo en la Cumbre de Copenhague sobre Cambio Climático de diciembre de 2009. Si hasta entonces se daba por buena la afirmación de que si los Estados miembros llegaban a un acuerdo lograrían imponerse en las instituciones internacionales, Copenhague muestra que la UE ya no es un actor decisivo de la gobernanza internacional ${ }^{58}$. No deja de ser la constatación de la pérdida de poder internacional desde Occidente hacia los emergentes y el anuncio de una deriva hacia la irrelevancia de Europa ${ }^{59}$.

En respuesta al contexto internacional y europeo, el modelo que Zapatero propondría para su política exterior se enmarcaba en una dimensión ética y normativa en torno a nociones como la fuerza del derecho, la legitimidad democrática, la solidaridad, la justicia social, el multilateralismo o el pacifismo. "Una clara opción europeísta; el respaldo a la legalidad internacional que representan las Naciones Unidas; la conciencia de una pertenencia activa a la Comunidad Iberoamericana de Naciones; una política global en la región mediterránea dirigida a promover el diálogo y la cooperación con todos los países de la región y a impulsar una resuelta acción a favor de una solución justa y duradera del conflicto árabe-israelí y, naturalmente, el reconocimiento de la importancia del dialogo trasatlántico en condiciones de equilibrio y autonomía con los EEUU incluida su vertiente bilateral. Así mismo, la lucha contra el terrorismo y el crimen organizado han sido siempre referencias sólidas de nuestra política exterior" ${ }^{\prime 60}$. Todo ello se traduciría en un giro en varias cuestiones de política exterior: la búsqueda del consenso doméstico en la formulación de la política exterior, una mayor participación de las Cortes Generales en política exterior y en defensa, la reformulación de las relaciones con Estados Unidos, Marruecos y el mundo árabe y la restauración de la dimensión política de las relaciones con América Latina, superando la visión de negocios de la etapa anterior.

Trató desde el primer momento de diferenciarse radicalmente del discurso en materia de política exterior de Aznar, al igual que de sus formas, tanto en la política internacional como en la política europea. Si el comienzo del ejercicio del poder de Zapatero está enmarcado en esta dimensión normativa, hay que subrayar que posiblemente ha evolucionado a posiciones mucho más pragmáticas y cercanas a la "real-politik" a lo largo de su mandato. Sólo así puede encontrarse una explicación a decisiones recientes como la participación en la operación que la OTAN está desarrollando en Libia en apoyo de los rebeldes a Gadafi desde marzo de 2011 o el anuncio de que la base naval de Rota acogerá parte del escudo antimisiles propuesto desde Estados Unidos y que tanto criticara cuando era una propuesta de Bush aceptada por Aznar.

Desde la dimensión normativa de su concepción de la política exterior, ante el contexto de la amenaza terrorista basada en el "choque de civilizaciones" según las tesis de Huntington, Zapatero respondería planteando en 2005 en unión con Turquía a la Asamblea General de Naciones Unidas su propuesta de "Alianza de Civilizaciones", que resultaría

\footnotetext{
${ }^{58}$ El Informe del Grupo de Sabios presidido por González hace un buen diagnóstico de los factores que explican la pérdida de peso relativo de la Unión Europea en la escena internacional y propone algunas medidas para contrarrestar esta tendencia. Ese Informe fue presentado al Consejo Europeo de junio de 2010. Véase: Grupo de Reflexión sobre el Futuro de la UE en 2030 (2010), Informe al Consejo Europeo "Proyecto Europa 2030. Retos y oportunidades", Mayo de 2010.

59 Véase al respecto: Torreblanca, José Ignacio (2011): La fragmentación del poder europeo, Madrid, Política Exterior/Icaria; Youngs, Richard (2010): Europe's decline and fall. The struggle against global irrelevance, London, Profile Books.

${ }^{60}$ Partido Socialista Obrero Español (2004), op. cit., p. 13.
} 
aprobada ${ }^{61}$. Se trataría de una iniciativa para promover el diálogo entre culturas, civilizaciones y religiones con la finalidad de contribuir a una cultura de paz en los planos local, regional, nacional e internacional ${ }^{62}$. Los Estados miembros de la "Alianza" debían poner en marcha Planes Nacionales para incorporar sus objetivos y actuaciones ${ }^{63}$. Seis años después pocos resultados ha dado esta iniciativa, que ha pasado sin pena ni gloria, y que, desde luego, no parece haber el factor que haya contribuido a un clima de mayor seguridad internacional. Si en 2011 el terrorismo internacional de origen islamista es una amenaza menor que en 2004 es resultado de las políticas internacionales de seguridad y cooperación antiterrorista y no tanto de este tipo de iniciativas.

Zapatero haría de la "vuelta a Europa" y una política exterior acorde con la Unión Europea los ejes de su política exterior al llegar al Gobierno. Se promueve así "Una España europea en una Europa unida", apostando por la profundización federal del proyecto político europeo, promotora del Estado del bienestar y que sea un actor autónomo y potente en el mundo con capacidad de promover una política exterior fundamentada en valores ${ }^{64}$. La primera medida de aplicación de este ideario fue el apoyo incondicionado a la Constitución Europea. Posiblemente la voluntad de perseguir los ideales minaran la capacidad de negociación del Gobierno español.

Se anuncia, por tanto, un giro inmediato en la alianza con los Estados miembros, abandonándose el eje de los intergubernamentalistas Reino Unido-Italia-Polonia y volviendo a ser socio del eje francoalemán de Chirac y Schröeder, que habían liderado tanto el ejercicio de profundización constitucional como la oposición a las tesis norteamericanas frente a Irak. El problema de Zapatero es que esta política de alianzas no rendirá muchos frutos ya que el eje al año siguiente se desintegraría con la sustitución al frente de sus Gobiernos primero de Schröder por Merkel, y luego de Chirac por Sarkozy ${ }^{65}$. Tanto la crisis constitucional como la posterior crisis económica obligaría a los líderes de Francia y Alemania a colaborar para dotar de impulso a la Unión, pero el motor ya no funcionaría con la armonía de la etapa anterior. Esto se debe a tres causas, primero, los nuevos líderes no son tan europeístas como los anteriores. Segundo, la falta de sintonía evidente entre Merkel y Sarkozy, a pesar de la afinidad ideológica. Y, en tercer lugar, a la constatación de que en una Unión ampliada no basta el liderazgo de dos países, aunque sean los grandes, para poner en movimiento la maquinaria europea.

Sin embargo, la europeizada política exterior española no era incompatible ni con la iniciativa propia ni con el protagonismo español en foros multilaterales como Naciones Unidas. Bilateralmente, España sería un mediador importante en la crisis del Líbano. Esa misma línea llevaría en los años siguientes a reforzar la presencia española en la ONU, incrementando su contribución financiera y participando en la FINUL en el Líbano a partir del año 2006. Igualmente ha mantenido sus compromisos en otros marcos multilaterales, con

\footnotetext{
${ }^{61}$ Asamblea General de Naciones Unidas (2005): Documento Final de la Cumbre Mundial de las Naciones Unidas, Sexagésimo periodo de sesiones, 25 de octubre de 2005, pto. 144.

${ }^{62}$ Véase: Barreñada, Isaías (Coord.) (2006): Alianza de civilizaciones: seguridad internacional y democracia cosmopolita, Madrid, ICEI y Editorial Complutense.

${ }^{63}$ En el caso español se han implementado dos Planes Nacionales consecutivos de la Alianza. El primer Plan se aprobó en enero de 2008, mientras que el II Plan, aprobado en mayo de 2010 tendrá vigencia hasta el año 2014 , aunque no sabemos si seguirá siendo una prioridad para el Gobierno que salga de las urnas en noviembre de 2011 .

${ }^{64}$ Partido Socialista Obrero Español (2004), op. cit., pp. 16 y 17.

65 Angela Merkel, demócrata-cristiana reemplazaría al social-demócrata Schröder al frente de la Cancillería alemana en noviembre de 2005, mientras que Sarkozy sustituiría a Chirac al frente de la Presidencia francesa en mayo de 2007.
} 
la participación en operaciones de crisis de la OTAN como la Isaf en Afganistán o la KFOR en Kosovo y el impulso continuado a la Conferencia Iberoamericana.

La preferencia por el multilateralismo, en paralelo con la acción a través de la política exterior europea, ha llevado al Gobierno de Zapatero a reclamar desde 2008 un puesto permanente en el G-20, donde hasta el momento sólo tiene el estatuto de invitado, gracias al apoyo francés. Por mucho que la Unión Europea sea miembro de pleno derecho de esta institución, España no quiere ser representada exclusivamente por ella y busca también una presencia propia. En la misma línea sí consiguió en 2008 ingresar en el Fondo de Estabilidad Financiera, desde donde contribuye a promover la posición común de la Eurozona.

\subsection{España en la PESC y la PESC de España}

El marco de valores de Zapatero y de Aznar en relación a la política exterior española y el modelo de Unión Europea no pueden ser más diferentes. Parece así que conducirían a una política exterior diferente, aunque esto no ha sido completamente cierto. El hecho de que Zapatero afirmara que la PESC sería el marco de referencia de la política exterior española, en la práctica tampoco ha llevado a una política exterior española tan diferente en términos de resultados. Al revés pueden detectarse constantes con el periodo anterior en materia de europeización de la política exterior e, incluso, divergencias de los postulados normativos de Zapatero. Así, en este periodo vamos a constatar, al igual que en el periodo anterior, una ruptura de la política exterior española con los países centrales de la Unión en el caso del reconocimiento de Kosovo en 2008. En este caso, fueron los países centrales de la UE y no el Gobierno español los que se apartaron de las sucesivas posiciones comunes para apoyar la declaración unilateral de las autoridades kosovares.

\subsubsection{La europeización de la política exterior española: valores y ámbitos de actuación}

En líneas generales la "vuelta a Europa" que preconizaba Rodríguez Zapatero se ha caracterizado por un reforzamiento de la europeización top-down de la política exterior española. Dicho de otro modo, se percibe una alineación de la agenda exterior española con la europea a través de la asunción explícita en los marcos jurídicos españoles de los valores y principios de la PESC. Igualmente, puede percibirse una apertura de la política exterior española a nuevos ámbitos regionales y problemas horizontales como consecuencia de la pertenencia a la Unión y a la existencia de una política común europea.

El compromiso de Zapatero con la“vuelta a Europa” en materia de política exterior pronto haría visible tras la aprobación en diciembre de 2004 de la Directiva de Defensa Nacional y en 2005 de la Ley Orgánica de Defensa Nacional ${ }^{66}$. En ellas se circunscribe la defensa española en el marco de la seguridad europea y de la OTAN: "En cuestiones de seguridad y defensa, Europa es nuestra área de interés prioritario; somos Europa y nuestra seguridad está indisolublemente unida a la del continente". Incorpora explícitamente los principios, valores y prioridades de la Estrategia Europea de Seguridad de 2003, subrayando los principios específicos del multilateralismo efectivo y el pleno respeto de la legalidad internacional $^{67}$. La siguiente Directiva de Defensa Nacional de 2008 sigue la misma línea, enumerando incluso las mismas amenazas de la Estrategia Europea. Cabe, por tanto, sostener

\footnotetext{
${ }^{66}$ Directiva de Defensa Nacional 1/2004, 30 de diciembre de 2004 y Ley Orgánica 5/2005, de 17 de noviembre, de la Defensa nacional, BOE no 276, de 18 de noviembre de 2005.

${ }^{67}$ Véase: Consejo Europeo (2003): “Una Europa Segura en un mundo mejor” Estrategia Europea de Seguridad, Copenhague, 12 de diciembre de 2003.
} 
la europeización de la política de seguridad y defensa española al asumir en sus bases las directrices políticas dictadas en el plano común.

La cooperación para el desarrollo va a resultar una de las señas de identidad de la política exterior de Zapatero, comprometida con los valores. Esta política española cambiará sustancialmente respecto al Gobierno anterior tanto en términos de diseño estratégico como en el incremento muy sustancial de recursos. Su característica será la internacionalización y la europeización. Se dirigirá la cooperación hacia la consecución de los Objetivos de Desarrollo del Milenio, aprobados por las Naciones Unidas a iniciativa de los países de la UE. Seguirán las pautas y las obligaciones asumidas en el marco de la política europea de desarrollo, incorporándose los principios y objetivos del Consenso Europeo de Desarrollo, las directrices en materia de eficacia de la ayuda y los compromisos financieros asumidos de cara a la Cumbre de Monterrey de $2005^{68}$.

Los Gobiernos de Zapatero continúan la senda marcada por Aznar de plena implicación en la PESD, tanto en el desarrollo de esta política, en materia de cooperación en capacidades y en la participación en misiones. En primer lugar, inicialmente España manifestaría su interés por tener una participación relevante en la Agencia Europea de Defensa, creada en 2004 como vigencia anticipada de la Constitución Europea ${ }^{69}$. Si bien España en un inicio no participó en la creación de un mercado común de la defensa, como consecuencia de los requerimientos de su industria, pronto esa situación se solventaría y a partir de 2007 se adheriría al Código de Conducta que rige el mercado europeo de defensa. En materia de capacidades, el Gobierno español anunciaría su disposición a formar parte de la Gendarmería europea creada en 2006 en Vincenza ${ }^{70}$ y el contribuir al Objetivo de Helsinki con su participación en tres battlegroups, uno en solitario y dos multinacionales. En paralelo se continuaría enviando tropas o efectivos civiles a las Operaciones Petersberg de la UE en los Balcanes, África y Asia, tomando parte España bajo el Gobierno de Zapatero en trece nuevas misiones civiles y militares de la Unión Europea.

Entre los ámbitos de política exterior que entraron en la agenda española como consecuencia de la pertenencia a la UE destacan los Balcanes. España tradicionalmente no ha tenido un papel diferenciado en la región por carecer de intereses específicos. Por tanto, se limitaba a formular su política de acuerdo con las líneas de la política europea ${ }^{71}$. Esta tendencia se rompería en 2008 , en que se separaría de la posición de los países centrales de la UE en relación a la independencia declarada por las autoridades kosovares en febrero de 2008. En este caso, hay que subrayar la lealtad española a la previa posición común europea, reiterada a lo largo de los años, que apoyaba la solución negociada y el desacato de los demás. España defendería incluso ante el Tribunal Internacional de Justicia las tesis de la ilegalidad de la Declaración, aunque finalmente el pronunciamiento consultivo sería contrario.

\footnotetext{
${ }^{68}$ En este sentido, véanse los Planes Directores de la Cooperación Española 2004-2008 y 2009-2012.

${ }^{69}$ Acción común 2004/551/PESC del Consejo, de 12 de julio de 2004, relativa a la creación de la Agencia Europea de Defensa.

${ }^{70}$ La agrupación multinacional Eurogendfor está compuesta por las policías de naturaleza militar de Francia, Italia, Portugal, Países Bajos y España (Guardia Civil) con la función de desarrollar operaciones no sólo de la UE, sino también de la OTAN, de la OSCE y de Naciones Unidas.

${ }^{71}$ Sobre las luces y las sombras de la política europea hacia Kosovo, véase: Bono, Giovanna: "The European Union and "supervised independence" of Kosovo: a strategic solution to the Kosovo/Serbia conflict?", European Foreign Affairs Review, vol. 15, no. 2 (2010), pp. 149-264; Keukeleire, Stephan, Kalaja Arben y Çollaku, Artan (2011): "The European Union $\square$ s Policy on Kosovo", en: Koutrakos, Panos (ed.), European Foreign Policy: Legal and Political Perspectives, Cheltenham, Edward Elgar, pp. 172-202.
} 
Sobra explicar que son razones domésticas las que están detrás de la resistencia española a reconocer al Estado kosovar. El Gobierno aún hoy se resiste a aceptar esta realidad junto con una minoría (tres) de Estados miembros, esperando que tengan éxito las negociaciones entabladas entre serbios y kosovares a instancias de la Alta Representante Ashton. La divergencia respecto a Kosovo tuvo como consecuencia la decisión española de no participar en la operación europea EULEX-Kosovo y de retirarse de la KFOR de la OTAN, aunque mantuvo su presencia en la UNMIK de Naciones Unidas. La cuestión de Kosovo, por tanto, supone un quiebro en la europeización de la política española hacia los Balcanes.

En esta época comienzan a aparecer temas nuevos en la agenda exterior española, vinculados al desarrollo de políticas europeas que formando un bucle terminarán por crear intereses españoles concretos a defender en una segunda dirección de europeización. Sería el caso de las relaciones con Rusia, donde inicialmente España no tiene preferencias, pero que entrarían en el marco de la política exterior española de la mano de los acuerdos rusoargelinos en materia gasística, vinculándose pronto esa política a los intereses españoles en la política energética exterior. En materia de seguridad energética y cambio climático, inicialmente puede detectarse una europeización top-down, pero después se interpreta en clave de intereses propios que se fomentan en Europa, produciéndose una europeización de doble vía ${ }^{72}$.

\subsubsection{La influencia de España en la Política Exterior Común: áreas de interés y problemas}

Si en el apartado anterior constatábamos un incremento de la adaptación de la agenda exterior española al marco común europeo, en este epígrafe puede comprobarse que, por el contrario, en este ámbito la influencia de España en la Política Exterior Común se ha reducido. Las causas no son achacables en exclusiva a las estrategias y la eficacia del Gobierno de Rodríguez Zapatero, sino sobre todo debidas al contexto ${ }^{73}$. Así, la Unión ampliada recorta sustancialmente la capacidad de un Estado como España de ejercer influencia. Esto se percibe con claridad en el caso de la política española hacia América Latina. Por el contrario, la pérdida del rol dinamizador en el Mediterráneo está causada por el creciente protagonismo francés y las limitaciones en la mediación en el conflicto de Oriente Medio vinieron de la oposición de otros socios, como Reino Unido o Alemania.

En el plano constitucional, Zapatero seguiría la línea de Aznar de respaldar plenamente todas las innovaciones en materia de la institucionalización de la PESC y los nuevos instrumentos de la PESD, como se deduce del ya estudiado firme apoyo español a la vigencia primero de la Constitución y luego del Tratado de Lisboa. Puede subrayarse especialmente la contribución de la Presidencia española, que se examinará con detalle más abajo, a la puesta en marcha de las nuevas instituciones de política exterior, facilitando tanto la asunción de competencias por las mismas como el desarrollo de dinámicas de cooperación interinstitucional. Esto es especialmente relevante en el caso del nuevo Servicio Europeo de Acción Exterior, verdadero Ministerio de Asuntos Exteriores, donde la Presidencia española jugó un papel decisivo en la mediación en la negociación para aprobar la Decisión de constitución ${ }^{74}$. En segundo lugar, podríamos hablar también de una especie de influencia "refleja" de España en el plano constitucional derivada de los atentados del 11-M. Estos llevaron a que el Consejo Europeo en marzo de 2004 aprobara el acuerdo político de

\footnotetext{
${ }^{72}$ Barbé, Esther (2008): "Pensar diferente, actuar en Europa...", op. cit., p. 15.

${ }^{73}$ Véase al respecto: Ibid., Ídem.

${ }^{74}$ Lefèvre, Maxime y Hillion, Christian (2010): The European Service for External Action: Towards a Common Diplomacy?, SIEPS European Policy Analysis, Swedish Institute for European Policy Studies, p. 4.
} 
activación de la cláusula de solidaridad para el caso de atentado terrorista como vigencia anticipada del artículo 42 de la Constitución Europea ${ }^{75}$.

En el plano de la exportación de políticas, hemos avanzado una cierta "deseuropeización" bottom-up, o pérdida de la influencia española para promover acciones políticas para sus áreas de interés. En primer lugar, las relaciones con América Latina van a perder relevancia en la política exterior europea debido al nuevo contexto de la ampliación y la globalización. El interés europeo se desplaza hacia la vecindad Este y hacia zonas conflictivas del planeta, dedicándose menos atención y recursos económicos a un área que no es prioritaria. España poco puede hacer para revertir esta tendencia, minada su credibilidad entre los europeos en cierta manera por las relaciones privilegiadas que establecería el primer Gobierno Zapatero con los Gobiernos de Chávez, Castro, Morales y Correa.

Además, es preciso tener en cuenta el peso de los nuevos países que vienen de la esfera de influencia soviética en la decisión europea que minan los esfuerzos españoles. Las dificultades planteadas por los países del Este obstaculizarían en diversas ocasiones la intención española de revisar la política europea hacia Cuba restaurando las relaciones políticas $^{76}$. Igualmente tampoco se lograría aprobar una posición común para mediar en el conflicto desatado por el golpe de Estado en Honduras en julio de 2009. El voluntarismo de la Presidencia española de preparar cuidadosamente la agenda permite que en 2010 se revierta algo la tendencia, lográndose importantes resultados de la Cumbre de Madrid de la Asociación Eurolatinoamericana.

Una de las prioridades de Zapatero era restaurar las relaciones con los países árabes y Marruecos y, por tanto, convertirse en un actor relevante en el Mediterráneo. Logró así de la Presidencia británica la celebración en Barcelona de la Cumbre euromediterránea de noviembre de 2005, con la finalidad de dar relevancia al décimo aniversario de la Asociación ${ }^{77}$. Esta Cumbre, minada por el conflicto de Oriente Medio, fracasó en impulsar el proceso, ya que sólo logró aprobar un programa de trabajo de cinco años basado en propuestas generales sin un compromiso financiero suficiente. Junto a Francia lograría colocar a estos países en el nuevo marco de la Política Europea de Vecindad.

El Mediterráneo resurgió en la agenda europea de la mano de Sarkozy con el proyecto de la Unión por el Mediterráneo, lanzado durante su campaña electoral, y que desembocaría en una profundización de la Política Europea de Vecindad hacia esta zona con un reforzamiento institucional y una dimensión multilateral ${ }^{78}$. Aunque España luchó por mantener un puesto hegemónico en su tradicional política exterior europea no ha podido evitar, en ningún momento, ir a remolque de Francia, e incluso de Alemania, en este área, por mucho que consiguiera renombrar el proyecto, mantener el legado del Proceso de Barcelona y que la sede de la nueva Secretaría General se estableciera en esta ciudad. Años después, esta Unión no puede calificarse más que de fracaso y por las mismas razones que explican la

\footnotetext{
${ }^{75}$ Consejo Europeo (2004): Declaración sobre la lucha contra el terrorismo, Bruselas, 25 de marzo de 2004, pto. 2 y declaración anexa. La cláusula de solidaridad hoy día se recoge en el artículo 222 del Tratado de Funcionamiento de la Unión.

${ }^{76}$ Barbé, Esther (2008): "Pensar diferente, actuar en Europa...", op. cit., p. 15.

${ }^{77}$ Para una valoración de los resultados de la Cumbre Euromediterránea, véase: Barbé, Esther y Soler i Lecha, Eduard (2005): "Barcelona + 10: Spanish Relaunch of the Euro-Mediterranean Partnership", The International Spectator, April-June.

${ }^{78}$ En relación a la Unión para el Mediterráneo, véase: Khader, Bichara (2009): Europa por el Mediterráneo: de Barcelona a Barcelona (1995-2009), Barcelona, Icaria; Garrido Rebolledo, Vicente y López Bueno, José María (co.) (2010): Política Euromediterránea: el Mediterráneo tras el Tratado de Lisboa, Madrid, Universidad Francisco de Vitoria.
} 
frustración del proceso de Barcelona. La nula capacidad de dinamización de España y los efectos destructivos del conflicto de Oriente Medio quedan patentes por el hecho de que tuviera que anular la Cumbre prevista en su Presidencia.

Respecto a la transferencia de problemas, España ha continuado promoviendo una acción europea en materia de lucha contra el terrorismo, si bien ha cambiado la óptica respecto a los Gobiernos de Aznar. Éste insistía en integrar la cooperación en materia antiterrorista en la esfera de la PESC y la PESD, incluso en su ámbito militar. Por el contrario, el Gobierno socialista preferirá enmarcar esta prioridad en la cooperación policial y, por tanto, sacarlo del ámbito de la política exterior para pasarlo al de la política interior europea ${ }^{79}$.

La inmigración y la gestión común de fronteras, por el contrario, sí han ganado en fuerza como prioridad española a promover en el marco de la política exterior europea, lo que pronto se vinculará con las relaciones con el África Subsahariana ${ }^{80}$. Se sigue así el impulso inicial de tiempos de Aznar, pero que se consolida en este periodo ${ }^{81}$. Así, la Cumbre informal de Hampton Court debatiría a iniciativa franco-española una política global europea sobre inmigración. Acordaría la vigilancia multilateral de las fronteras exteriores de la UE por la recién creada Frontex, la firma de acuerdos de readmisión entre la UE y terceros países de origen o tránsito y doblar la cooperación para el desarrollo destinada a los países del África Subsahariana. Estos acuerdos serían redondeados por las decisiones del Consejo Europeo de diciembre de 2006, también a iniciativa española, Posteriormente, se impulsaría la creación de un fondo para abordar situaciones derivadas de la presión migratoria que se activaría en 2006 para Canarias.

La acción común a través de Frontex tiene y ha tenido una importante actividad en el control de los flujos migratorios ilegales en el Estrecho y hacia Canarias, desarrollándose una operación conjunta en 2006 en Canarias (Hera) para frenar la oleada de cayucos. España también impulsó con éxito la reflexión sobre la problemática de la migración ligada al desarrollo organizando la primera Conferencia Euro-Africana sobre Migración y Desarrollo en Rabat en 2006. Como consecuencia de este interés, la política exterior española comenzaría a interesarse por el África Subsahariana, incorporando a su vez una línea política europea, retroalimentando el proceso de europeización.

Motivaciones también de protección de intereses españoles estarían detrás del impulso español junto a Francia para la puesta en marcha de la Operación Petersberg EUNAVFORSomalia (Atalanta) en 2009 con la finalidad de luchar contra la piratería en el Golfo de Adén. Se han utilizado los recursos europeos para tratar de afrontar el problema de la seguridad de los pesqueros españoles que faenan en las aguas del Índico y, por tanto, dar respuesta a los intereses estratégicos y económicos españoles.

\footnotetext{
${ }^{79}$ En este sentido, España es uno de los siete países que firman originalmente el Tratado de Prüm en 2005 para reforzar la cooperación transfronteriza en materia de lucha contra el terrorismo, la delincuencia transfronteriza y la inmigración ilegal y al que después se han adherido más Estados miembros.

${ }^{80}$ En relación a estas cuestiones véase: Bermejo, Rut y Argomaniz, Javier (co.) (2010): "El Espacio de Libertad, Seguridad y Justicia de la UE: un balance entre Presidencias españolas (2002-2010)", Revista Cidob d'Afers Internacionals, $\mathrm{n}^{\circ} 91$.

${ }^{81}$ En tiempos de Aznar se había dado impulso a la creación de una Agencia para la gestión de la cooperación operativa en las fronteras exteriores de la UE, conocida como Frontex, que finalmente vería la luz con la aprobación de su Reglamento en octubre de 2004.
} 


\subsection{La Presidencia española de 2010: las ambiciones chocan con la realidad}

El eje fuerte en materia de política exterior del segundo Gobierno Zapatero lo constituía la Presidencia Española del primer semestre de 2010, dentro de la cual la vertiente exterior constituía uno de los ejes fundamentales. Las ambiciones del Gobierno español eran elevadas: sus portavoces no se cansaron de anunciar que se trataría de una Presidencia ambiciosa, de transformación y no meramente de gestión de la agenda institucional europea ${ }^{82}$. Ni el contexto de crisis económica, ni las circunstancias políticas, ni los resultados permiten una valoración muy positiva, teniéndonos que contentar con la apreciación de que los modestos resultados de la Presidencia fueron debidos sobre todo al contexto ${ }^{83}$.

De los dos escenarios que barajaban -con o sin Tratado de Lisboa-, a la Presidencia le tocó poner en marcha las innovaciones institucionales del Tratado, que tendrían importantes consecuencias para su propio papel de liderazgo. La creación de la figura del Presidente permanente tiene como consecuencia que nuestro país haya dejado de presidir el Consejo Europeo, convirtiéndose en esta etapa exclusivamente en "Presidencia del Consejo de la UE", una institución no principal. Incluso en este marco, la instauración del rol del Alto Representante de la UE para los Asuntos Exteriores y la Política de Seguridad ha implicado que el Consejo de Asuntos Exteriores haya dejado de estar presidido por España, lo que tiene consecuencias en el liderazgo de la agenda exterior ${ }^{84}$. La tercera innovación institucional de Lisboa es la Presidencia por equipos, que inauguró España, y que para dar continuidad a la agenda europea supone que un trío de países ejerza esta función de forma coordinada con un Programa común y apoyándose mutuamente ${ }^{85}$.

El hecho de que España ejerciera esta labor con plena "lealtad institucional" ha jugado en contra de sus intereses, ya que ha perdido protagonismo especialmente en la conducción de la política exterior y el diseño de la agenda. Ha perdido en visibilidad, ya que el país no preside las Cumbres con terceros ni lidera la negociación. Esto tiene efectos también en la presencia en terceros Estados, ya que como consecuencia del nuevo Tratado la representación exterior de la PESC ha resultado transferida de las Embajadas de los Estados miembros a las Delegaciones de la UE, lo que también comenzó a implementarse bajo Presidencia española. Sin embargo, se ha alabado el buen hacer español en la transición institucional y su colaboración para poner en marcha dinámicas de cooperación entre las instituciones responsables que constituye un precedente muy valioso para el nuevo sistema de gobernanza de la política exterior europea ${ }^{86}$.

Es preciso, en cualquier caso, valorar muy positivamente el papel de la Presidencia española en la negociación de la Decisión de creación del Servicio Europeo de Acción

\footnotetext{
${ }^{82}$ En relación a la ambiciosa agenda de la Presidencia española, véase: López Garrido, Diego, "La Presidencia española del Consejo de la Unión Europea”, en: Aldecoa Luzárraga, Francisco, González Alonso, Luis Norberto y Guzmán Zapater, Mónica (co.) (2009): La Presidencia española de la Unión Europea en 2010: propuestas para una agenda ambiciosa, Madrid, Marcial Pons, pp. 17-23.

${ }^{83}$ Para una valoración de los logros de la Presidencia española: Barbé Izuel, Esther (ed.) (2011): Entre la irrelevancia internacional y el aprendizaje institucional: La presidencia española de la Unión Europea (2010), Barcelona, Universidad Autónoma de Barcelona; Heywood, Paul M. (2011): "Spain's EU Presidency: Ambitions beyond Capacity?", Journal of Common Market Studies, vol. 49, Supl. 1, pp. 77-89.

${ }^{84}$ La Presidencia rotatoria sí mantiene la Presidencia del Consejo de Asuntos Generales que en algunas de sus competencias tiene importancia en política exterior, ya que se ocupa de temas como la Ampliación.

${ }^{85}$ Véase: The future Spanish, Belgian and Hungarian Presidencies (2009): 18 Month Programme of the Council, Brussels, 17 November (16771/09).

${ }^{86}$ Molina, Ignacio: 'Innovating Europe' in Troubled Times: A First Assessment of Spain's EU Presidency in 2010, Real Instituto Elcano, ARI 115/2010 (2010).
} 
Exterior, que se aprobó en el tiempo récord de cuatro meses ${ }^{87}$. La labor de mediación desarrollada por los responsables españoles fue clave, a juicio de los protagonistas, para alcanzar el "Acuerdo de Madrid" que fundamentaría la regulación del nuevo organismo y que llevaría al consenso entre el Parlamento, los Estados miembros y la Alta Representante ${ }^{88}$.

Los objetivos en materia exterior que se había planteado la Presidencia española en su programa no pudieron cumplirse ni de lejos ${ }^{89}$. Esto se debió fundamentalmente a que ya no se tenía la posición institucional para desarrollar una agenda y a la crisis económica y la crisis de deuda griega que desplazó las prioridades y centró buena parte de la actividad institucional en resolver la catástrofe inminente. También se ha criticado la falta de realismo del programa, que hay que leerlo más como un manifiesto electoral que como un conjunto de propuestas que pudieran ponerse en marcha es un espacio de tiempo tan corto como son seis meses ${ }^{90}$. La realidad es que ya no tiene sentido que las Presidencias semestrales elaboren una agenda exterior que ya no está en sus manos implementar pues han perdido la función de iniciativa en este terreno.

El fracaso más llamativo fue la decisión de Estados Unidos de suspender la Cumbre que iba a ser celebrada en Madrid en mayo y que había sido preparada durante más de dos años por el Gobierno español que veía una oportunidad de oro para impulsar las relaciones bilaterales ${ }^{91}$. Por parte de Obama se argumentó una agenda cargada de temas domésticos, pero trascendió la incomodidad del Gobierno estadounidense con la complejidad de la nueva representación exterior europea y la multiplicación de Cumbres sin resultados palpables. Sin embargo, en el plano de la cooperación antiterrorista España logró, no sin relevantes obstáculos, renovar los acuerdos Open Sky y "Swift" logrando un compromiso del Parlamento Europeo

En el marco de las relaciones con el Mediterráneo y América Latina se ha percibido que se ha intentado transferir un buen número de prioridades nacionales a la agenda europea ${ }^{92}$. Los resultados han sido opuestos en ambos ámbitos. A España le tocaba organizar la Segunda Cumbre de la Unión para el Mediterráneo, que fue programada para junio. Se decidió su aplazamiento para evitar su fracaso a causa del conflicto palestino-israelí, el recrudecimiento de las tensiones en Gaza y la falta de nuevas propuestas de cooperación.

En sentido contrario, el éxito mayor de la Presidencia española lo constituye, sin duda alguna, la Cumbre con América Latina, que alcanzó relevantes resultados, a pesar de la sonora ausencia de algunos de los líderes latinoamericanos ${ }^{93}$. Como se deseaba, se logró pactar una nueva agenda para la Asociación birregional, que incluye un nuevo objetivo de cooperación, la innovación tecnológica y un Plan de Acción verificable en su cumplimiento. Además, se

\footnotetext{
${ }^{87}$ Decisión del Consejo de 26 de Julio de 2010 por la que se establece la organización y el funcionamiento del Servicio Europeo de Acción Exterior, DO L 201, de 3.8.2010, p. 30.

${ }^{88}$ Véase al respecto: Guinea Llorente, Mercedes: "El Servicio Europeo de Acción Exterior: génesis de una diplomacia europea", Revista de Derecho Comunitario Europeo, no 37 (2010), pp. 761-800.

${ }^{89}$ Véase: Presidencia Española del Consejo de la UE (2009): “Innovando Europa” Programa de la Presidencia española del Consejo de la UE, Madrid, BOE, pp. 11-13.

${ }^{90}$ Haywood (2011), op. cit, p. 79.

${ }^{91}$ Para una revisión detallada de toda la actividad exterior de la Presidencia española, véase: Secretaría de Estado para la Unión Europea (2010): Balance de la IV Presidencia Española del Consejo de la Unión Europea, Madrid, BOE, pp. 15-63.

${ }^{92}$ Fernández Sola, Natividad y Sorroza Blanco, Alicia: "La UE en el mundo: actuaciones y limitaciones de la presidencia española 2010”, Real Instituto Elcano ARI 82/2010 (2010).

93 Sobre los desafíos de la Asociación Birregional, véase: Nuevas bases para las relaciones entre la Unión Europea y América Latina y el Caribe, Madrid, FIIAPP (2010).
} 
concluyeron relevantes acuerdos comerciales como el Acuerdo de Asociación con Centroamérica y los Acuerdos comerciales multipartes con Colombia y Perú. En paralelo se retomaron las negociaciones para un Acuerdo de Asociación con MERCOSUR. Igualmente se ha reforzado la institucionalidad de la Asociación, lanzando un Mecanismo de Inversión para América Latina -nueva línea de financiación de la iniciativa empresarial- y la Fundación EULAC con la finalidad de dar impulso continuado a la asociación.

En conclusión, la Presidencia española, la primera del contexto "post-Lisboa", puede ser calificada con toda justicia de "Presidencia de transición" $"$. Ha mostrado en toda su magnitud el nulo papel que resulta para las presidencias semestrales de los Estados miembros consecuencia de las disposiciones institucionales del nuevo Tratado. Dado que se ha perdido el diseño de la agenda, la dirección del diálogo político, la ejecución y la representación de la PESC, a partir de este momento dejará de ser útil preguntarse por el papel de las Presidencias rotatorias en política exterior.

\section{Conclusiones: constantes y divergencias de la participación española en la Política Exterior Común europea}

La década 2001-2011 es una década compleja y convulsa para tanto la propia Unión Europea y su política exterior como para la participación de España en la misma. En este periodo asistimos a dos Gobiernos con visiones y marcos normativos diferentes en materia de política exterior europea. Aznar, dados sus desencuentros especialmente con Francia en asuntos europeos, priorizará los intereses españoles y la conveniencia de tener relaciones privilegiadas con una potencia como la estadounidense. Esta opción determina su posición hacia el proyecto europeo y su disposición a separarse de la posición del eje franco-alemán en el planteamiento sobre la invasión militar a Irak. Zapatero, por el contrario, hará del marco de la política exterior europea su referente para intentar enmarcar la política exterior española en términos de valores. Ambos, sin embargo, mantendrán una importante actividad bilateral y en foros multilaterales en paralelo a la política exterior europea.

Si examinamos las líneas políticas conducidas por ambos Gobiernos se aprecian relevantes constantes. Por razones diferentes -Aznar instrumentales, Zapatero de compromisoambos apoyan y contribuyen al desarrollo de los instrumentos de la PESC y la PESD, entendiendo la conveniencia de una política exterior europea fuerte. Ambos seguirán promoviendo las áreas tradicionales de influencia española, el Mediterráneo y América Latina, si bien desde perspectivas diferentes y con resultados distintos. De igual manera, desde los dos Gobiernos se entenderá la oportunidad que supone la acción común europea para promover intereses españoles, sean comerciales, relativos a la inmigración o a la seguridad.

La europeización ha evolucionado en términos similares en ambos periodos. La topdown va creciendo exponencialmente lo que se debe a varios factores de distinto peso y alcance. En primer lugar, un elemento estructural, el incremento de la identidad común afianzada en una mayor interdependencia de todos los Estados miembros. En segundo lugar, otro coyuntural, la adopción voluntaria de Rodríguez Zapatero de los marcos normativos comunes y las directrices aprobadas en sede comunitaria. Esto no obsta para que en el caso

\footnotetext{
${ }^{94}$ Barbé Izuel Esther: "Introducción. Entre la irrelevancia internacional y el aprendizaje institucional: Un marco de análisis para la Presidencia española de la Unión Europea”, en: Barbé Izuel (2011), op. cit., pp. 15-22.
} 
concreto de Kosovo se produzca una desviación de esta tendencia por intereses nacionales concretos.

Finalmente, en el marco de la europeización bottom-up se detecta en los años finales del periodo analizado un descenso o pérdida de influencia de España en la política exterior común. Aquí también los factores que lo explican son diversos. Dos de ellos son de naturaleza estructural: la pérdida de peso relativo de un país como España en la Unión ampliada y el hecho de que las Presidencias semestrales ya no sirvan para impulsar las preferencias de política exterior de los Estados miembros en la política exterior común. Los otros dos elementos coyunturales se refieren a la pérdida de influencia de un país minado por la crisis económica y a la falta de eficacia de un Gobierno que no ha hecho de la política exterior su prioridad, lo que se detecta en una disminución de su capacidad negociadora. Falta ahora por ver la visión y estrategia política que desplegará ante la política europea el Gobierno que salga de las urnas el 20 de noviembre de 2011. 